PONTIFÍCIA UNIVERSIDADE CATÓLICA DO RIO DE JANEIRO

\title{
AVALIAÇÃO DE EMPRESAS: ESTUDO DE CASOS DA EMPRESA LOJAS AMERICANAS
}

Viktor Waissmann de Araujo

Trabalho de Conclusão de Curso

Centro de Clências socials - CCS

DePARTAMENTO de AdMINISTRAÇÃo

Graduação em Administração de Empresas 
Viktor Waissmann de Araujo

\section{Avaliação de Empresas: Estudo de caso da empresa Lojas Americanas}

Trabalho de Conclusão de Curso

Trabalho de Conclusão de Curso, apresentado ao programa de graduação em Administração da PUC-Rio como requisito parcial para a obtenção do titulo de graduação em Administração.

Orientador: Prof. Luiz Brandão

Rio de Janeiro

Novembro de 2017. 


\section{Resumo}

Araujo, Viktor Waissmann.. Avaliação de Empresas: Estudo de Caso da Empresa Lojas Americanas S.A. Rio de Janeiro, 2017. Número de páginas 36p. Trabalho de Conclusão de Curso - Departamento de Administração. Pontifícia Universidade Católica do Rio de Janeiro

Avaliação de empresas é uma ferramenta muito importante para a tomada de decisões, no que diz respeito à compra e venda de negócios, cisões e incorporação de empresas, fusões, gestão de carteiras de ativos, dissoluções de sociedades, entre outros. Diante disso, este estudo tem por objetivo avaliar o valor da empresa Lojas Americanas S.A, através da aplicação da avaliação por fluxo de caixa descontado, estimar o valor real de mercado da mesma, garantindo a avaliação e interpretação adequada de tais dados de modo a permitir o acompanhamento da performance da empresa e prever suas tendências. Este trabalho justifica-se à medida em que estimar o valor de mercado de uma empresa envolve vários critérios que necessitam ser analisados. Os resultados indicam que o valor de mercado está próximo ao encontrado através desta avaliação.

Palavras-chave: Lojas Americanas; Avaliação; Fluxo de caixa descontado 


\section{Abstract}

Araujo, Viktor Waissmann.. Avaliação de Empresas: Estudo de Caso da Empresa Lojas Americanas S.A. Rio de Janeiro, 2017. Number of pages 36. Trabalho de Conclusão de Curso - Departamento de Administração. Pontifícia Universidade Católica do Rio de Janeiro.

Firm valuation is an important tool for making decisions regarding to the purchase and sale of businesses, divisions and incorporation of companies, mergers, portfolio management of assets, dissolution of companies, among others. Therefore, the purpose of this study is to determine the value of Lojas Americanas S.A, through the application of the discounted cash flow method, to estimate the market value of the firm and ensuring the proper evaluation and interpretation of such data in order to monitor the performance of the company and predict its trends. This work is justified to the extent that estimating the real market value of a company involves several criteria that need to be analyzed. The results suggest that the current market price of the shares is within the expected value.

\section{Key-words: Lojas Americanas; Valuation; Discounted cash flow}




\section{Sumário}

1 O tema e o problema de estudo 1

1.1. Introdução ao tema e ao problema do estudo 1

1.2. Objetivo do estudo 1

1.3. Justificativa e relevância do estudo 2

1.4. Limitações do Estudo 2

2 Referencial Teórico 3

2.1. Perfil da empresa 3

2.1.1. Contexto operacional das Lojas Americanas 5

2.2. Avaliação de empresas por Fluxo de Caixa Descontado 8

2.3. Abordagens de Avaliação por Fluxo de Caixa Descontado 14

2.3.1. Abordagem do Fluxo de Caixa do Acionista 14

2.3.2. Estimativas de Taxas de Desconto de Custo de Capital Próprio 15

2.3.2.1. Modelo de Crescimento de Dividendos 16

2.3.2.2. Abordagem do Fluxo de Caixa da Empresa 17

2.3.2.3. Estimativa da Taxa de Desconto do Custo Médio Ponderado de Capital 17

2.3.2.4. Efeitos da Combinação de Taxas de Desconto Inadequadas 18

2.3.2.5. Limitações do Fluxo de Caixa Descontado 18

3 Métodos e procedimentos de coleta e de análise de dados do estudo 20

3.1. Procedimentos e instrumentos de coleta de dados utilizados no estudo 20

3.2. Formas de tratamento e análise dos dados coletados para o estudo20

4 Valuation das Lojas Americanas $\quad 21$

4.1. Fluxo de Caixa Descontado $\quad 21$

4.1.1. Projeções Macroeconômicas 21

4.1.2. Custo da dívida (Kd) 21

4.1.3. Custo de Capital Próprio (Ka) 23

4.1.4. WACC - Weighted Average Capital Cost (Custo Médio Ponderado do Capital) 
4.1.5. Premissas de Crescimento 25

4.1.6. CAPEX e Depreciação \& Amortização 26

4.1.7. Capital de Giro 28

4.1.8. EBITDA e EBIT 30

4.1.9. Valor presente dos fluxos operacionais 30

4.1.10. Perpetuidade 30

4.1.11. Valor da Empresa e para os acionistas 31

4.1.12. Valor das Ações 31

5 Conclusões 32

6 REFERÊNCIAS 33

$\begin{array}{ll}\text { ANEXO 1 } & 36\end{array}$

$\begin{array}{lr}\text { ANEXO } 2 & 37\end{array}$ 


\section{Lista de Figuras}

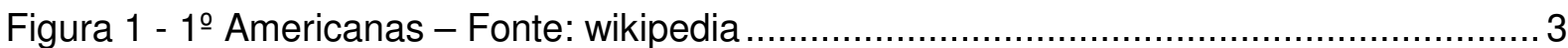

Figura 2 - Estrutura B2W - Fonte: B2W relações com investidores ................................... 4

Figura 3 - Estrutura multicanal da Americanas - Fonte: Relatório Anual Lojas

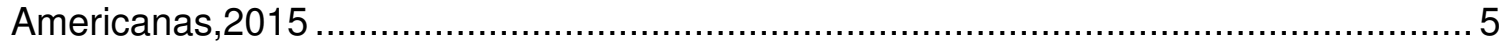

Figura 4 - Distribuição das lojas pelo Brasil - Fonte Relatório Anual, 2016 ......................... 6

Figura 5 - Receita Líquida de Vendas e Serviços - Relatórios anuais, site LASA relações

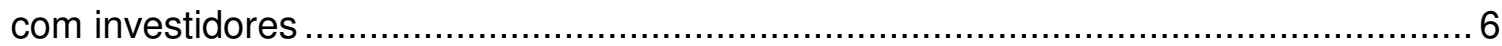

Figura 6 - Índice de confiança do consumidor - Fonte: FGV, 2016 .................................. 7

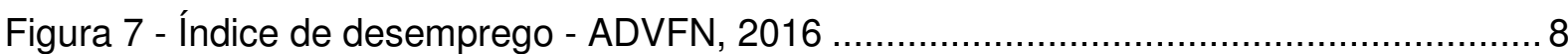

\section{Lista de Tabelas}

Tabela 1 - Nível de crescimento ano a ano (2013 a 2016) - Fonte: relatórios anuais ............ 7

Tabela 3 - Estrutura da divida LASA 2013 a 2016 - Fonte: Relatórios anuais ..................... 22

Tabela 4 - Peso da composição da dívida - Fonte: Relatórios anuais ................................ 22

Tabela 5 - Custo de crédito - Fonte: Relatórios anuais …............................................ 22

Tabela 6 - Custo da dívida - Fonte: Relatórios anuais....................................................... 23

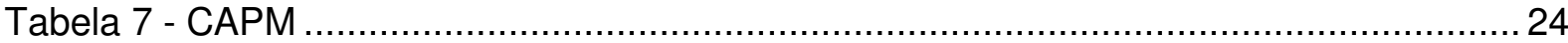

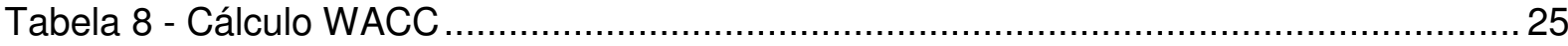

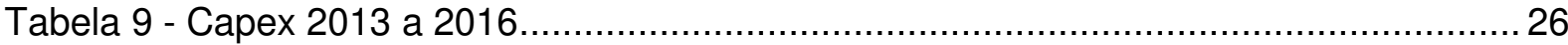

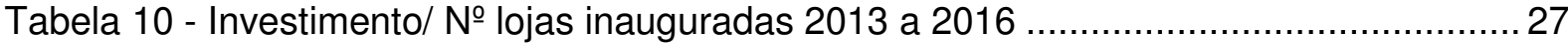

Tabela 11 - CAPEX Projetado Plano "85 Anos em 5" ....................................................... 27

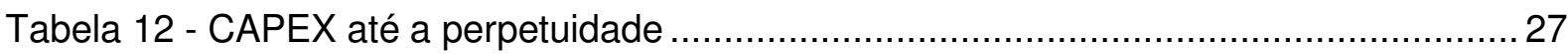

Tabela 13 - Projeção Capital de Giro ................................................................................. 29

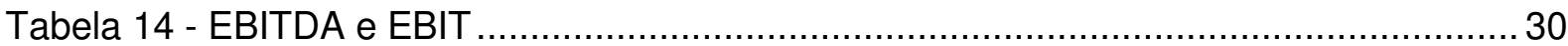

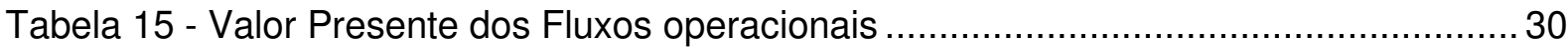

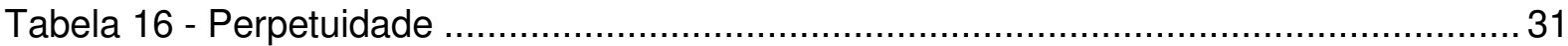

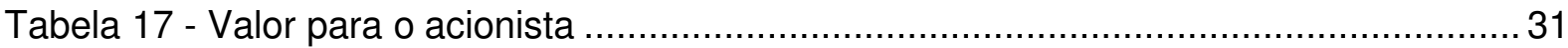

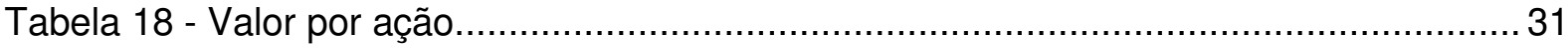

\section{Lista de Equações}

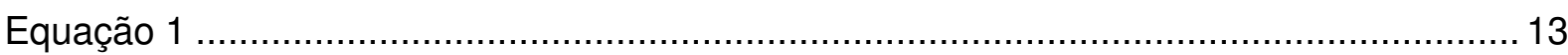

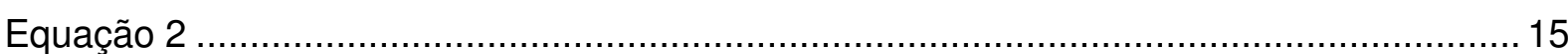

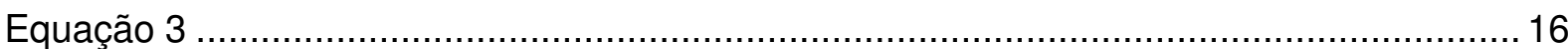


Equação 4 16

Equação 5 


\section{0 tema e o problema de estudo}

\subsection{Introdução ao tema e ao problema do estudo}

A Avaliação de Empresas é um metodologia muito importante, tornandose ferramenta imprescindível para a tomada de decisões em relação a compra e venda de negócios, cisões e incorporação de empresas, fusões, gestão de carteiras de ativos, dissoluções de sociedades, aberturas iniciais de capital conhecidas como IPOs (Initial Public Oferings), emissões públicas de novas ações, oferta pública de aquisição chamada OPA, entre outros.

A capacidade de gerar valor é parte essencial do desenvolvimento de estratégias corporativas e empresariais sólidas. Dessa forma, os gestores que se concentram na geração de valor constroem empresas mais bem sucedidas (COPELAND et al, 2002).

Para Damodaran (2009) há três abordagens para a avaliação: avaliação por fluxo de caixa descontado, segundo a qual o valor de uma empresa é determinado pelo fluxo de caixa projetado, descontado por uma taxa que reflita o risco associado ao investimento; avaliação relativa ou por múltiplos, na qual avaliamos um ativo com base em como ativos semelhantes são precificados no mercado através da utilização de múltiplos (ex: razões preço/lucro, razões valor da empresa/EBITDA, razões preço/vendas); e finalmente avaliação de opções reais, que inclui no valor final o valor de possíveis decisões que podem ser tomadas ao longo do projeto, como abandono, expansão, desinvestimento, entre outros.

\subsection{Objetivo do estudo}

Objetiva-se com esse trabalho, através da aplicação da avaliação por fluxo de caixa descontado da empresa objeto do estudo, estimar o valor de mercado da mesma e compará-lo com o valor real, analisando e compreendendo as diferenças. 


\subsection{Justificativa e relevância do estudo}

Este trabalho justifica-se na medida em que cada vez mais as empresas têm entrado no mercado de capitais e o aumento da popularidade da bolsa entre investidores brasileiros. Além disso, estimar o valor real de mercado de uma empresa envolve vários critérios que necessitam ser analisados e esse estudo terá a chance de observar as diferenças entre o resultado baseado apenas na teoria acadêmica ensinada no curso de administração na PUC-Rio e os valores encontrados atualmente no mercado, no caso de que essas diferenças de fato existam.

\subsection{Limitações do Estudo}

A mais evidente limitação do estudo é a dependência de informações públicas divulgadas, que mesmo em conformidade com o exigido pela legislação ou até superando o mínimo requerido, ainda desconsideram as decisões estratégicas que podem ser tomadas pela empresa, como expansão, entrada em novos mercados, desinvestimentos, etc.

Além disso, uma vez que o mercado não é eficiente, o preço encontrado no modelo pode não estar de acordo com o real uma vez que podem existir investidores menos informados ou impulsivos, assim como podem existir alguns que possuem informações privilegiadas.

Essas limitações, no entanto, não invalidam o estudo, pois as informações disponíveis são suficientes para que a metodologia seja aplicada 


\section{Referencial Teórico}

\subsection{Perfil da empresa}

A Lojas Americanas foi fundada em 1929 em Niterói (RJ), por John Lee, Glen Matson, James Marshall e Batson Borger, norte-americanos de nascimento.

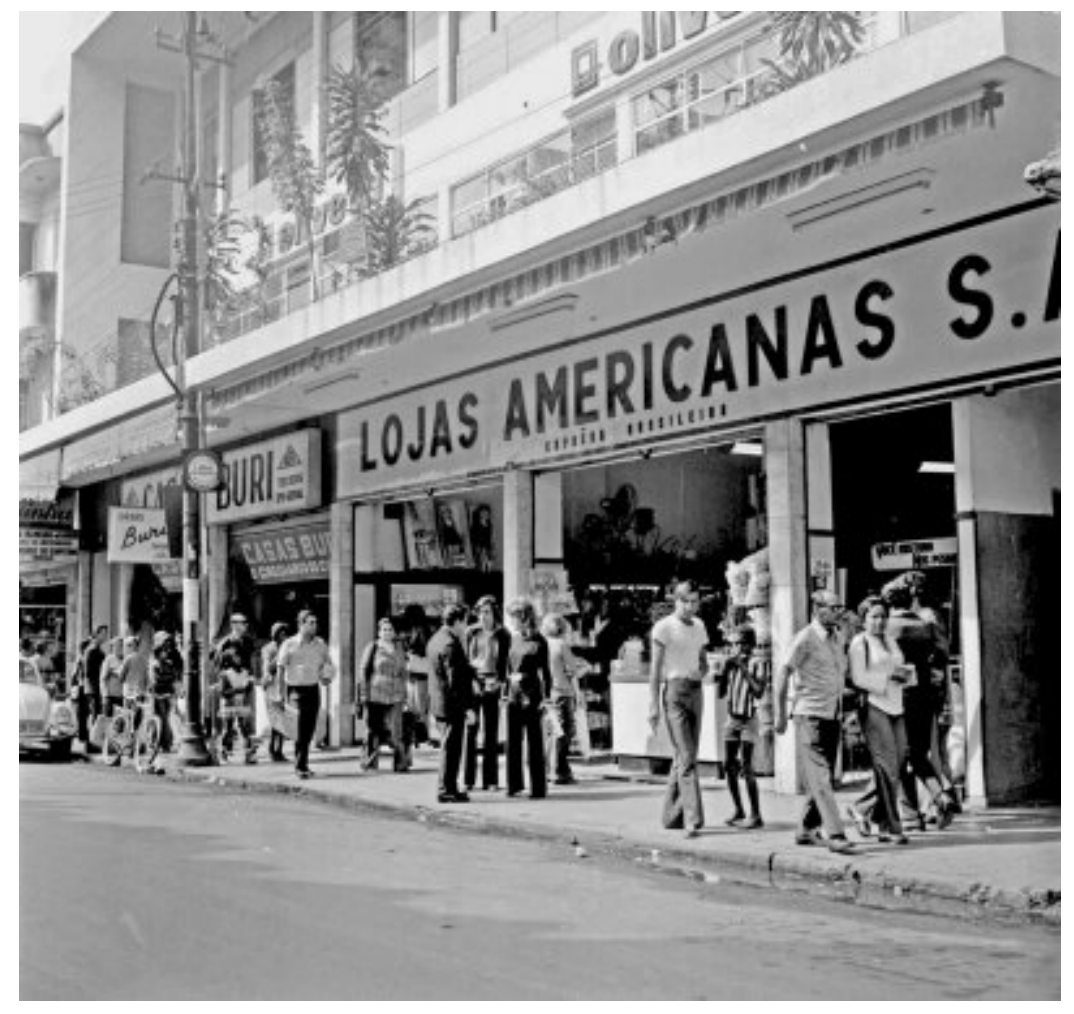

Figura 1 - 1ํAmericanas - Fonte: wikipedia

A empresa tornou-se sociedade anônima de capital aberto em 1940 e seu controle transferido em 1982 para o Banco Garantia, banco de investimentos criado por Jorge Paulo Lemann. Hoje é controlada pela 3G Capital, uma empresa de private equity brasileira-estadunidense criada em 2004, fundada e controlada até hoje por Marcel Telles, Jorge Paulo Lemann e Carlos Alberto Sicupira.

A empresa criou seu braço de comércio eletrônico em 1999, a Americanas.com, comprou o canal e site de vendas Shoptime em 2005 e a varejista eletrônica Submarino em 2006. Ainda em 2006 as 3 empresas se juntam para formar 
uma nova, a B2W digital, que atua em canais de vendas como internet, televendas, quiosques, catálogos e TV. A nova empresa começou sua expansão internacional em 2009, pelo México, e alcançou a Argentina e o Chile em 2010.

\section{LOJAS AMERICANAS}
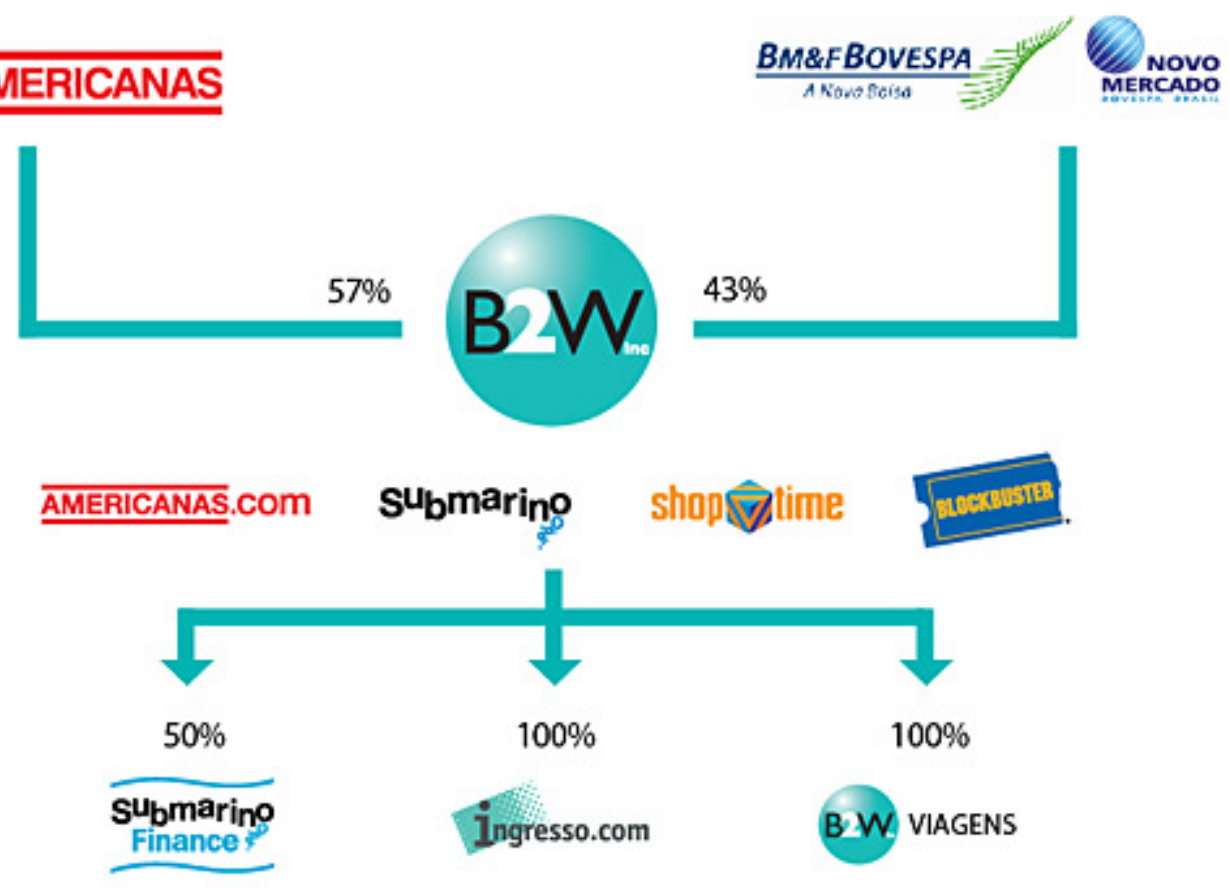

Figura 2 - Estrutura B2W - Fonte: B2W relações com investidores

Hoje as lojas americanas detêm controle da B2W com 57\% do capital social, enquanto os outros $45 \%$ são negociados na Bovespa por meio do código BTOW3, no segmento Novo mercado, reservado para das empresas que se encontram no mais avançado nível de governança corporativa e que se comprometem, de forma voluntária, a adotar práticas que excedem as exigências da legislação, no que se refere à governança corporativa e direitos dos acionistas. A empresa controladora ainda é negociada no Nível 2, através dos códigos LAME3, para ações ordinárias com direito a voto, e LAME4, para ações preferenciais sem direito a voto.

A sede atualmente fica no Rio de Janeiro e comercializa 80 mil itens de mais de 2 mil fornecedores em todo o Brasil. 


\subsubsection{Contexto operacional das Lojas Americanas}

As Lojas Americanas é uma rede de varejo multicanal. Isso porque, além das lojas físicas, atua também via internet, televisão, televendas, catálogos e quiosques.

A figura 3 ilustra como funciona essa rede multicanal. O primeiro grupo inclui duas marcas: Lojas Americanas e Americanas Express. O segundo inclui a holding B2W digital e suas marcas Americanas.com, Submarino, Sou Barato e Shoptime, responsáveis pelos canais sem loja física.

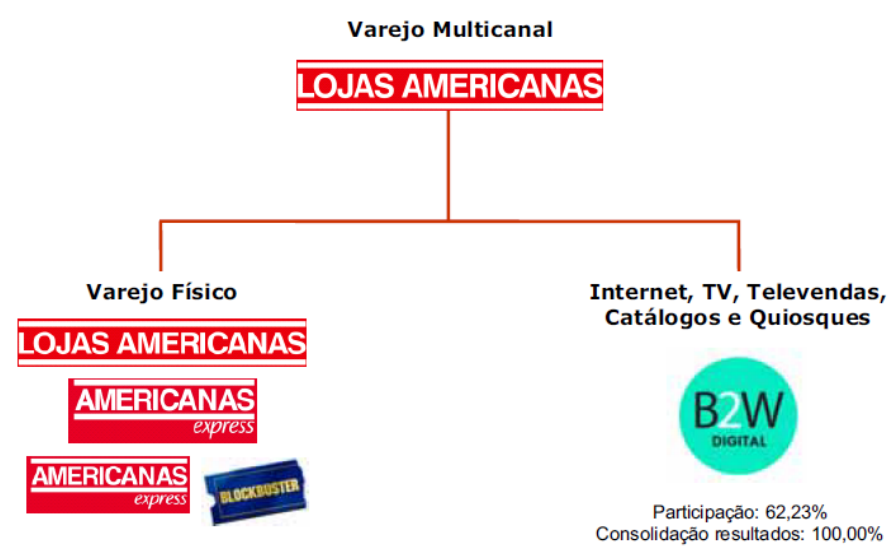

Figura 3 - Estrutura multicanal da Americanas - Fonte: Relatório Anual Lojas Americanas,2015

O braço de varejo físico opera através de 1.145 lojas (em 31 de dezembro de 2016 - 1.127 lojas) totalizando 980,2 mil metros quadrados de área de vendas, sendo 739 lojas no modelo tradicional e 406 lojas no modelo Americanas Express, presentes em 446 cidades em todos os estados do Brasil e abastecidas por centros de distribuição localizados em Minas Gerais, Pernambuco, Rio de Janeiro e São Paulo.

Conforme descrito no gráfico abaixo as lojas estão localizadas principalmente no Sudeste (54\%) e Nordeste (21\%). 


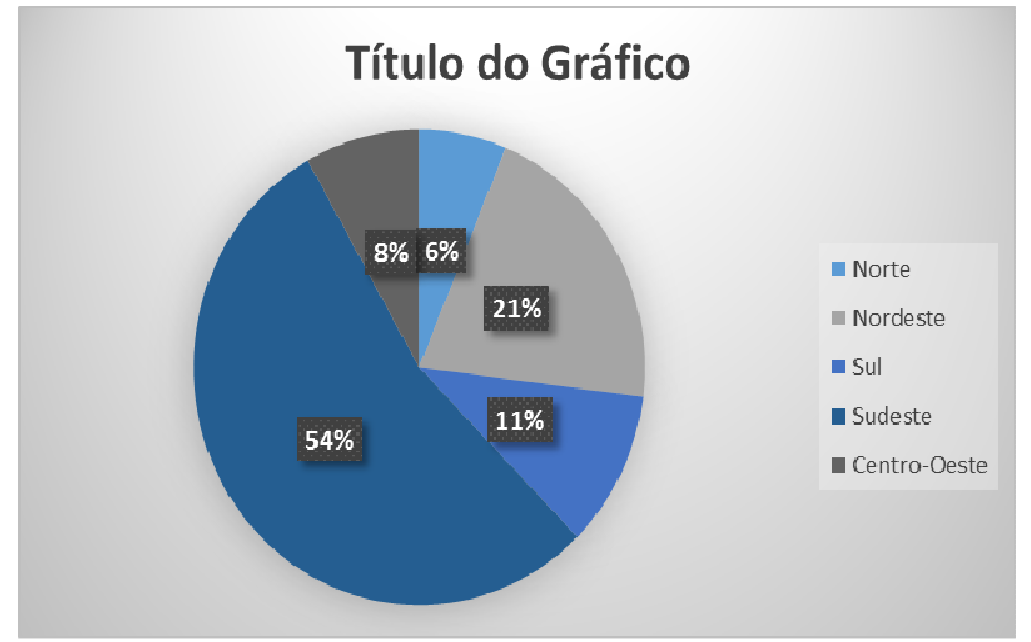

Figura 4 - Distribuição das lojas pelo Brasil - Fonte Relatório Anual, 2016

No ano de 2013, mesmo diante da instabilidade econômica, a empresa obteve um resultado de $\mathrm{R} \$ 13,401$ bilhões de receita líquida consolidada, o que representa um crescimento de 18,2\% comparando com o período anterior. Deste montante, $\mathrm{R} \$ 7,716$ bilhões se referem ao desempenho da controladora (Lojas Físicas), que apresentou vendas 12,6\% a mais que em 2012. No ano de 2014 o resultado da receita bruta consolidada foi de $R \$ 16,145$ bilhões (crescimento de $20,5 \%$ ). No ano de 2015 esse resultado foi de $R \$ 17.926$ bilhões (crescimento de $11 \%)$.

A figura 5 ilustra o resultado da receita líquida de vendas e serviços (em bilhões de reais) no período de 2013 a 2016.

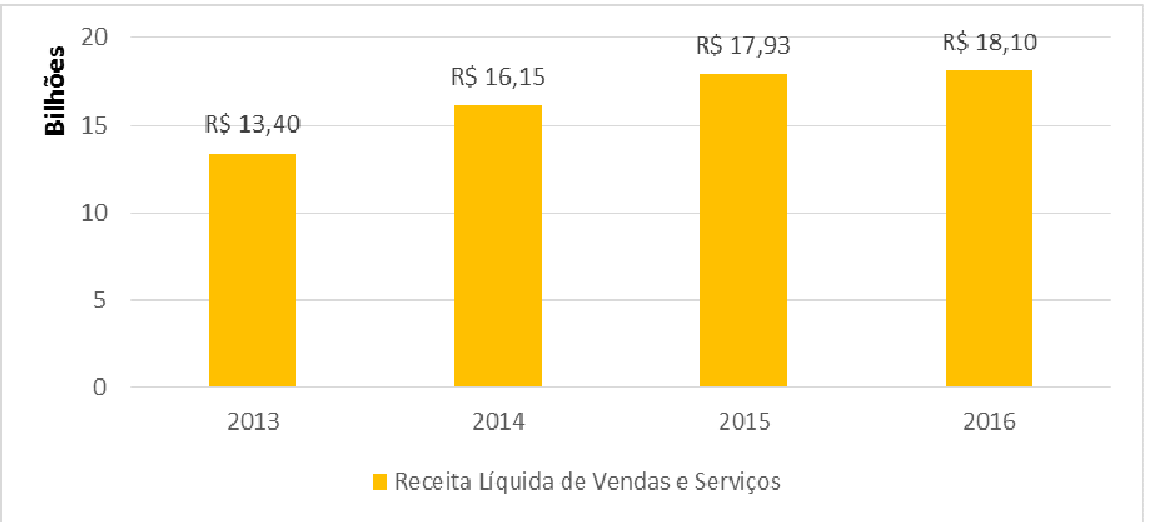

Figura 5 - Receita Líquida de Vendas e Serviços - Relatórios anuais, site LASA relações com investidores 
O quadro 2 ilustra o nível de crescimento no mesmo período em porcentagem.

\begin{tabular}{|c|c|c|c|}
\hline \multicolumn{4}{|c|}{ Crescimento } \\
\hline $\begin{array}{c}\text { Receita Bruta de Vendas e } \\
\text { Serviços }\end{array}$ & $1913-2014$ & $2014-2015$ & $2015-2016$ \\
\hline Lucro Bruto & $18,7 \%$ & $11,9 \%$ & $3,3 \%$ \\
\hline $\begin{array}{c}\text { Resultado Operacional antes } \\
\text { do Resultado Financeiro e } \\
\text { Equivalência }\end{array}$ & $13,8 \%$ & $6,0 \%$ & $5,3 \%$ \\
\hline Lucro Liquido do Período & $6,3 \%$ & $-41,5 \%$ & $-15,4 \%$ \\
\hline
\end{tabular}

Tabela 1 - Nível de crescimento ano a ano (2013 a 2016) - Fonte: relatórios anuais

Ao avaliar a receita bruta de vendas e serviços, verifica-se claramente que o nível de crescimento foi diminuindo ao longo desse período, passando de 19,7\% em 2014 para 3,3\% em 2016. Essa queda é reflexo da crise econômica na qual o país se encontra, graças a qual o varejo teve a maior queda de resultado em 16 anos, retrocedendo ao nível de 2012. Os maiores responsáveis por isso foram a inflação alta, o desemprego elevado e a diminuição do índice de confiança do consumidor.

Com a economia instável e o com índice elevado de desemprego, o índice de confiança do consumidor sofreu uma queda muito grande, como pode ser visualizada na figura 6 .

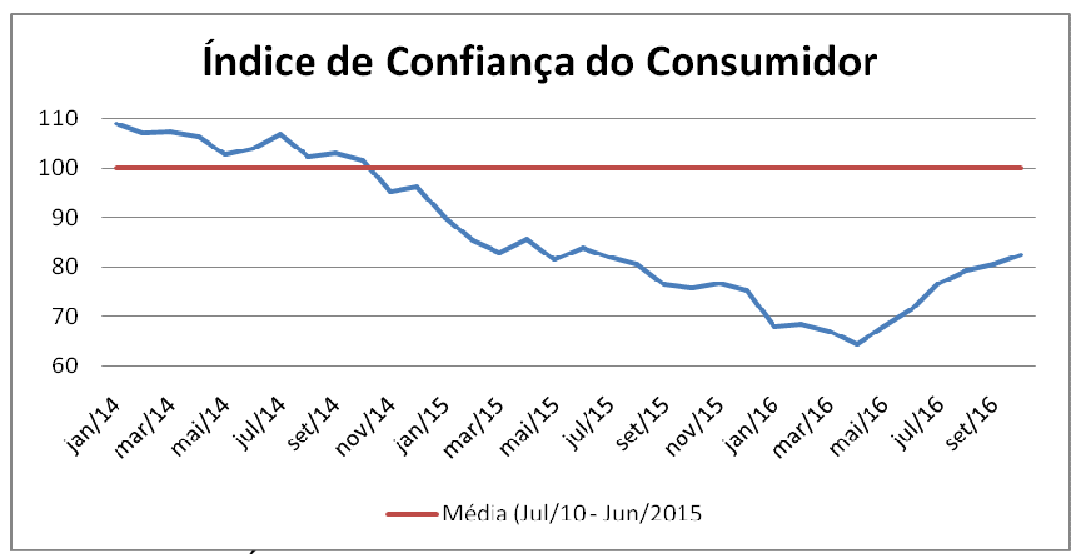

Figura 6 - Índice de confiança do consumidor - Fonte: FGV, 2016 
O gráfico 2 ilustra que o pior índice de confiança pelo consumidor foi registrado em abril de 2016 e a partir de maio do mesmo ano começou a dar sinais de melhora.

Como dito anteriormente, a principal causa dessa desconfiança por parte do consumidor é o nível de desemprego. O gráfico 3 ilustra o índice de desemprego tendo como base o período de Janeiro de 2015 e Setembro de 2016.

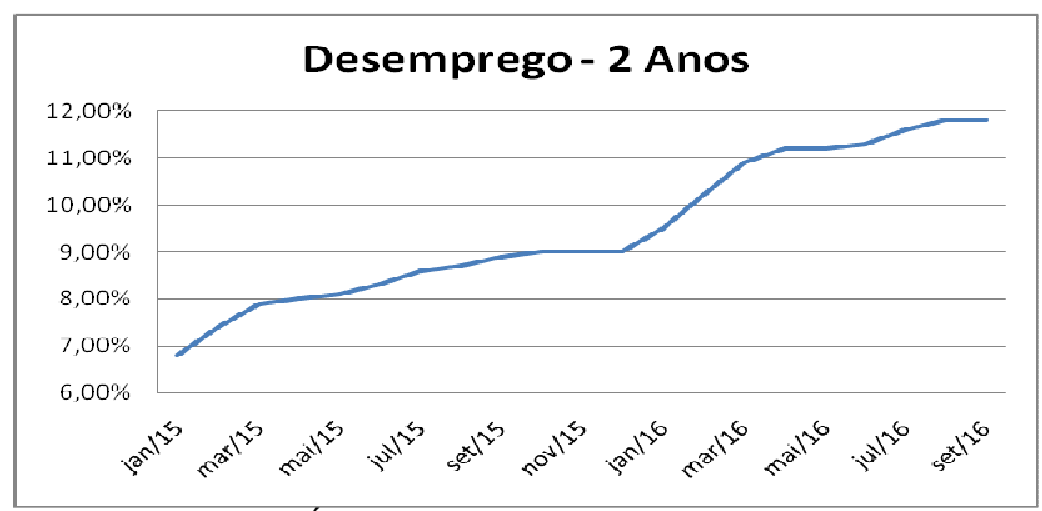

Figura 7 - Índice de desemprego - ADVFN, 2016

\subsection{Avaliação de empresas por Fluxo de Caixa Descontado}

Em toda organização a equação financeira que aborda a expansão e/ou a manutenção da atividade produtiva vai depender da harmonia existente entre os recursos operacionais, os recursos de terceiros e os aportes de capital pelos acionistas. Tais recursos são responsáveis pela estrutura econômico-financeira da empresa (CATAPAN \& HEIDEMANN, 2002).

Para Casarotto Filho \& Hopittke (2007), os recursos para investimento são provenientes de diversas fontes, tais como os recursos próprios (advindos dos acionistas), empréstimos e debêntures. Já o retorno que estes recursos auferem advêm dos lucros e juros gerados pelas operações da empresa.

Cabe salientar que segundo Catapan \& Heidemann (2002), o valor atribuído às empresas tem sido alvo de controvérsia, uma vez que embora essencial, a avaliação das empresas é, geralmente pouco consensual. Ela é 
determinada normalmente pelo método do fluxo de caixa descontado, o qual traz os fluxos financeiros futuros a valores presentes, utilizando-se uma taxa de desconto derivada do custo de capital da empresa.

Sobre esta metodologia, afirma Martinez (1997, p.122) ao explanar acerca dessa metodologia explica que:

O mercado avalia os ativos pelo seu potencial de geração de caixa, por um
período determinado, em geral ao redor de 30 anos. Uma usina geradora
vale, portanto, a receita que poderá auferir neste período, menos as
despesas, trazidas ao valor presente.

Já Martins (2001) acredita que o valor econômico de qualquer patrimônio é correspondente ao valor presente do fluxo líquido de caixa aliado ao que se objetiva que esse mesmo patrimônio produza no futuro. Isso ocorre porque o alvo é sempre o caixa e o que importa é o futuro.

Deve-se levar também em consideração a importância dos dados de entrada ou premissas de uma avaliação. Entretanto, tais premissas vão sofrendo interferência de diversos fatores, que afetam o custo de capital, e devido a isso por diversas vezes não se ajustam adequadamente em modelos determinísticos.

Diante disso, Casarotto Filho \& Kopittke (2007), assinalam que na prática podem ocorrer casos em que as incertezas sobre os dados de entrada e a estimativa de vendas e do custo de capital, necessitam ser analisadas sob condições de risco. Nesse caso é necessário recorrer a modelos probabilísticos.

Assaf Neto (2008) afirma que a determinação do custo do capital acionário é utilizada visando outras finalidades avaliativas. Como exemplo, exemplifica a avaliação do desempenho econômico de empresas, mediante métodos como o EVA (economic value added), que também depende da estimativa do custo do capital próprio. Igualmente na avaliação de investimentos, a definição do retorno mínimo, que supere o custo do capital, necessita da estimativa de custo do capital dos acionistas.

Segundo Endler (2004), a avaliação de uma organização realizada utilizando o Fluxo de Caixa Descontado se baseia na teoria de que o valor de um 
empreendimento depende dos benefícios futuros trazidos pelo mesmo, descontados para um valor presente, por meio do uso de uma taxa de desconto apropriada, que enumere quais os riscos relativos aos fluxos estimados. Levando-se em consideração que as organizações não possuem prazo de vida determinado, o cálculo de seu valor é tem como base a estimativa de fluxos infinitos. Diante disso, o valor em um instante de tempo "t" é o somatório dos valores presentes dos fluxos futuros, descontados por uma taxa que representa a taxa de retorno requerida.

Para Damodaran (2003), tal método é mais facilmente utilizado em organizações que apresentem fluxos de caixa positivos, que possam ser estimados de forma confiável para períodos futuros. Além disso, deve existir um substituto para risco que possa ser usado para a obtenção de taxas de desconto. O autor salienta que esta metodologia tem como característica a captura de todos os elementos que afetam o valor da empresa de maneira abrangente e, por constituir-se em uma técnica de natureza econômica, reflete de forma mais consistente o valor da empresa do que o valor obtido a partir de técnicas contábeis que se baseiam no lucro contábil e não levam em com ta o investimento exigido para gerar os lucros nem o momento em que eles ocorrem.

Entretanto, essa metodologia pode exigir algumas adaptações em função de certas circunstâncias, tais como:

a) Empresas em dificuldades financeiras. Uma empresa nessas condições normalmente possui um quadro de fluxos de caixa e resultados negativos, sendo incapaz de quitar passivos, acarretando dessa forma um grande volume de dívidas. Nesse caso, a avaliação da mesma através do fluxo de caixa descontado torna-se difícil. Desta forma, é necessário fazer algumas adaptações como avaliar a empresa em vez do Patrimônio Líquido, usar lucros normalizados ou médios, ou estimar fluxos de caixa para os períodos de transição. Cabe salientar que se a empresa apresentar indícios de falência, o método de Fluxo de Caixa Descontado não deverá ser utilizado. Em casos como este, utiliza-se o valor de liquidação ou modelos de avaliação de opções, sendo que este último 
método poderá tornar-se impraticável para a avaliação de empresas de pequeno e médio porte, em razão da complexidade dos dados de entrada necessários.

b) Empresas cíclicas. Nesse tipo de empresas os fluxos de caixa e os resultados seguem a tendência do comportamento da economia. Diante disso, pelo fato de não ter uma uniformidade, existe uma dificuldade de análise nos momentos de recessão por se apresentarem negativos. Levando em consideração esse cenário, a avaliação deve ter como base os desvios e tendências para uma análise coerente do valor da empresa.

c) Empresas com ativos não utilizados ou subutilizados. No caso de empresas com ativos não utilizados, o valor projetado da empresa não conseguirá refletir o valor desses ativos, pois estes não estão produzindo resultados. Já no caso de ativos subutilizados, o seu valor será subavaliado. Diante disso, é necessário apurar o valor de mercado desses ativos e adicioná-lo ao valor obtido na avaliação pelo fluxo de caixa descontado.

d) Empresas que possuem patentes ou opções de produtos. Nesse caso a empresa será subavaliada. Diante disso, tais ativos devem ser avaliados no mercado livre ou através da utilização de modelos de precificação de opções, além de ser adicionado o valor dessa avaliação ao valor obtido na avaliação através do fluxo de caixa descontado.

e) Empresas em processo de reestruturação. A avaliação desse tipo de empresa ocorre pelo fato de que geralmente as mudanças nela ocorrida acabam se refletindo na sua estrutura organizacional e de capital e isso torna muito difícil uma estimativa de fluxos de caixa futuro e afeta diretamente o grau de risco da empresa. Diante disso, os fluxos de caixa futuro dessa avaliação necessitam refletir os novos negócios e riscos causados pelas mudanças ocorridas. 
f) Empresas envolvidas em aquisições. Nesse caso é de suma importância que seja verificada a existência ou não de sinergia na combinação e se o seu valor pode ser estimado.

g) Empresas de capital fechado. Nesse caso específico, a dificuldade de avaliação reside na complexidade de medição do risco e taxa de desconto. Como as empresas de capital fechado não negociam seus títulos, existem duas alternativas: utilizar o grau de risco de empresas semelhantes que possuam ações em bolsa, ou relacionar o risco a variáveis contábeis da empresa.

Para Catapan \& Heidemann (2002), o custo de capital de uma organização vai depender de sua estrutura, ou seja, do mix de capitais que a estruturam. Pode-se definir o custo do capital como sendo o custo médio ponderado do capital próprio e do capital de terceiros, necessitando ser levado em consideração neste cálculo os impactos dos benefícios fiscais do imposto de renda e da contribuição social.

No que tange ao coeficiente, o custo do capital representa uma taxa mínima que a organização necessita obter em suas operações, indicando, dessa forma a remuneração mínima necessária a ser auferida para se manter o valor de suas ações.

Diante disso, Casarotto Filho \& Kopittke (2007) ressaltam que todas as empresas necessitam apresentar, uma taxa de retorno maior ou pelo menos igual à taxa do custo de capital da empresa. Isso fica claro quando os autores mencionam que os investimentos da organização necessitam render o suficiente para pagar os juros dos capitais de terceiros e proporcionar um lucro compatível com as expectativas dos acionistas.

De acordo com Coopeland et al (2000) é notório que tanto os credores quanto os acionistas buscam ser recompensados pelo custo da oportunidade de investirem seus recursos em um negócio. Os autores ressaltam ainda que em termos relativos, o custo médio ponderado do capital (weighted average cost of capital - WACC) é a taxa utilizada para descontar o valor do dinheiro no tempo, 
convertendo o fluxo de caixa futuro em seu valor presente, para todos os investidores.

Segundo Ross et al (2000), a fórmula utilizada para o cálculo do custo médio ponderado do capital (weighted average cost of capital - WACC) é expressado da seguinte forma:

\section{Equação 1}

$$
W A C C=K_{a} \frac{E}{V}+K_{d} \frac{E}{V}\left(1-T_{c}\right)
$$

Onde:

WACC $=$ taxa de custo médio ponderado do capital;

Tc = alíquota do imposto de renda e da contribuição social da pessoa jurídica;

$\mathrm{E}=$ valor de mercado do capital próprio da empresa (em $\mathrm{R} \$$ );

$\mathrm{D}=$ valor de mercado do capital de terceiros da empresa (em $\mathrm{R} \$$ );

$\mathrm{V}=\mathrm{E}+\mathrm{D}$ (valor de mercado do capital total, em $\mathrm{R} \$$ );

$\mathrm{E} / \mathrm{V}=$ proporção do capital próprio sobre o financiamento total da empresa (em valores de mercado);

$\mathrm{D} / \mathrm{V}=$ proporção do capital de terceiros sobre o financiamento total da empresa;

$\mathrm{Re}=$ custo do capital próprio (CAPM);

$\mathrm{Rd}=$ custo do capital de terceiros.

Segundo Ross et al (2000) o coeficiente do custo médio ponderado do capital da organização, nada mais é do que a taxa de retorno global exigida da mesma, ou seja, é a taxa de desconto certa a ser aplicada aos fluxos de caixa que têm risco semelhante ao da empresa como um todo. No que tange ao capital de terceiros, caso haja mais de um tipo de títulos de dívida, é necessário calcular cada tipo, sendo os resultados tratados de forma ponderada.

Coopeland et al (2000) mencionam ainda que todas as obrigações financeiras correntes da organização têm um custo de capital igual ao das outras formas de dívida, mas esse custo está implícito no preço pago aos insumos que as 
geram. Diante disso, acabam incluídos tanto nos custos operacionais como no fluxo de caixa da empresa. Somente os impostos que se aplicam a despesas com juros necessitam ser utilizados para compor a taxa de desconto. Já os outros impostos ou créditos deverão ser incorporados diretamente no fluxo de caixa.

Cabe salientar que para se obter as composições proporcionais das fontes de capital de uma empresa, é necessário que seja determinada a estrutura atual de capital da mesma, levando em consideração a proporção dos estoques existentes de dívidas e de capital próprio frente a seu capital total. No caso específico de avaliação das organizações, geralmente busca-se identificar uma estrutura de capital-alvo, procurando aumentar os efeitos dos benefícios fiscais inerentes no capital de terceiros. Entretanto, é de suma importância precaver-se contra o excesso de alavancagem financeira, sobretudo quanto aos riscos associados à dependência demasiada de recursos em moeda estrangeira.

\subsection{Abordagens de Avaliação por Fluxo de Caixa Descontado}

Segundo Endler (2004) a avaliação por Fluxo de Caixa Descontado pode ser realizada através de duas abordagens. Na primeira abordagem é avaliada apenas a participação acionária, ou seja, o valor para o acionista e a segunda abordagem a empresa é avaliada como um todo. Entretanto, cabe destacar que nas duas abordagens os fluxos de caixa esperados são descontados, mas com diferenciadas definições de fluxo de caixa e taxas de desconto.

\subsubsection{Abordagem do Fluxo de Caixa do Acionista}

Endler (2004) menciona que avaliação enfocando o Patrimônio Líquido ou - Fluxo de Caixa do Acionista, devem ser descontados os fluxos de caixa esperados do acionista após a dedução de todas as despesas, bônus fiscais, pagamento de juros e principal pela taxa de retorno exigida pelos investidores. 
Para a realização do cálculo de avaliação através do Fluxo de Caixa do Acionista utiliza-se a seguinte fórmula:

\section{Equação 2}

$$
V P L=\sum_{t=1}^{\infty} \frac{F C_{a}}{\left(1+K_{a}\right)^{t}}-\text { Investimento Inicial }
$$

Onde:

$\mathrm{VPL}=$ Valor Presente Líquido

$\mathrm{FCa}=$ Fluxo de caixa do acionista no período $\mathrm{t}$

$\mathrm{Ka}=\mathrm{WACC}$

\subsubsection{Estimativas de Taxas de Desconto de Custo de Capital Próprio}

Segundo Endler (2004), o custo de patrimônio líquido é a taxa de retorno exigida pelos investidores para realização de um investimento patrimonial em uma determinada organização. Caso o investimento em análise não trouxer um retorno maior que o oferecido por outros investimentos disponíveis no mercado financeiro, é certo que o investidor optará por outros melhores.

Um dos pontos de maior dificuldade no processo de avaliação das organizações reside no cálculo da obtenção do custo de capital próprio, uma vez que este necessita ser estimado através do processo, o que envolve um grau elevado de subjetividade com possibilidades da ocorrência de erros.

Para Damodaran (2003) existem duas abordagens para a estimativa do custo de capital próprio. A primeira é a aplicação de um modelo de crescimento de dividendos e a segunda é a utilização de um modelo de risco e retorno.

De acordo com Ross et al (2000), o melhor método para a obtenção do custo do capital próprio é a utilização de modelos de risco e retorno denominado de Capital Asset Pricing Model (CAPM), ou seja, trata-se de um modelo de precificação de ativos, calculado por meio de uma equação que mostra a relação entre retorno esperado e beta. Entretanto, o retorno esperado depende de três componentes, que podem ser vistos abaixo na equação 3 : 
a) $\mathrm{Rf}=$ Taxa livre de risco, a taxa que remunera um investimento sem risco assumido na economia;

b) $E(R m)-R f]=$ Recompensa por assumir risco sistemático: é medida pelo prêmio por risco de mercado, que corresponde a recompensa do mercado por assumir um risco;

c) $\beta=$ Nível de risco sistemático, representa o nível de risco sistemático presente em determinado ativo.

\section{Equação 3}

$$
K_{a}=R_{f}+\beta\left(E\left[R_{m}-R_{f}\right)\right.
$$

\subsubsection{Modelo de Crescimento de Dividendos}

Endler (2004) menciona que esse tipo de modelo é o meio mais fácil de ser utilizado e compreendido. No entanto, a sua utilização é limitada para avaliação de empresas que demonstrem situação de estabilidade, ou seja, que tenham crescimento constante. Para Ross et al (2000) o custo de capital próprio apresenta uma certa instabilidade com relação à taxa estimada de crescimento, além de não considerar o risco explicitamente. Diante disso, fica difícil saber se o retorno estimado é compatível com o nível de risco existente.

Segundo esse modelo, o cálculo do custo médio ponderado do capital é definido pela seguinte fórmula:

\section{Equação 4}

$$
K_{a}=\frac{D P S_{1}}{P_{0}}+g
$$

Onde:

ke = Custo do patrimônio líquido 
DPS1 = dividendos por ação esperados no ano seguinte

P0 = preço da ação na data da avaliação

$\mathrm{g}$ = taxa de crescimento dos dividendos (situação estável)

\subsubsection{Abordagem do Fluxo de Caixa da Empresa}

De acordo com Endler (2004) através dessa abordagem, obtém-se o valor presente da empresa como um todo, por meio dos fluxos de caixa esperados para a organização, descontados pelo custo médio ponderado de capital - Weighted Average Cost of Capital (WACC). Dessa forma, o cálculo do fluxo de caixa da organização é definido pela seguinte fórmula:

\section{Equação 5}

$$
V P L=\sum_{t=1}^{\infty} \frac{F C_{e}}{(1+W A C C)^{t}}-\text { Investimento }
$$

Onde:

$\mathrm{VPL}=$ Valor Presente Líquido

$\mathrm{FCe}=$ Fluxo de caixa da empresa no período $\mathrm{t}$

WACC $=$ Custo médio de capital ponderado (Weighted Average Cost of Capital)

\subsubsection{Estimativa da Taxa de Desconto do Custo Médio Ponderado de Capital}

Segundo Endler (2004) o custo médio do capital ponderado representa o valor do dinheiro no tempo, é geralmente usado para converter os fluxos de caixa futuros a um valor presente, ou seja, é o retorno exigido sobre seu capital investido para que a empresa atinja o equilíbrio na aplicação efetuada.

Nesse caso, a taxa apropriada de desconto a ser usada é a taxa mínima de retorno esperada que uma organização precisa oferecer para ser atraente. Entretanto essa taxa é subjetiva de forma intrínseca, uma vez que não propicia informações seguras e isso pode incidir em erros no cálculo de avaliação da 
organização. Diante disso, deve-se ter cuidado ao utilizar o WACC com o intuito de avaliar uma organização, pois se a taxa de risco não estiver avaliada de forma correta, acabará induzindo a erros de julgamento.

\subsubsection{Efeitos da Combinação de Taxas de Desconto Inadequadas}

As abordagens, tanto de enfoque da empresa quando de enfoque do acionista, mesmo usando diferentes fluxos de caixa e taxas de desconto, utilizam os mesmos pressupostos. Diante disso, os resultados dos cálculos de ambas levarão a estimativas consistentes de valor (ENDLER, 2004).

De acordo com Damodaran (2003) deve-se prestar atenção a um erro que geralmente ocorre por parte dos avaliadores que é o uso indevido das taxas de desconto. $\mathrm{Na}$ verdade, esse erro consiste na utilização de custo médio ponderado de capital para descontar fluxos de caixa para o patrimônio líquido e na utilização do custo do patrimônio líquido para descontar fluxos de caixa para a empresa.

\subsubsection{Limitações do Fluxo de Caixa Descontado}

De acordo com Assaf Neto (2008), a formulação do método do fluxo de caixa descontado tem como base o valor do dinheiro no tempo. Embora o fluxo de caixa descontado seja simples na sua essência, na sua utilização tem se mostrado complexo.

Tal complexidade se dá pelo fato de que ao se fazer a estimativa do fluxo de caixa futuro de uma organização, é necessário que haja uma estimativa do 
comportamento da economia como um todo. Isso propicia muitos erros na previsão das variáveis (ROGERS et al, 2004).

Segundo Tibúrcio \& Cunha (2002) dois avaliadores ao avaliarem uma mesma empresa, podem utilizar variáveis distintas e isso pode influenciar na avaliação.

Santos \& Pamplona (2001) salienta ainda que o grande problema deste modelo reside no fato de que ele não possibilita a captação do valor da flexibilidade administrativa, ou seja, quando os dados futuros são apresentados de forma diferente do que o previsto, o Fluxo de Caixa Descontado não tem como captar tais dados.

De acordo com Santos \& Pamplona (2001, p.3)

Executivos, percebendo que a ferramenta de FCD é muito pobre em captar possibilidades relevantes do projeto, se valem da intuição de negócios, não investindo imediatamente em projetos só por causa de uma análise estática ter indicado um Valor Presente Líquido positivo, e nem rejeitam projetos estratégicos só por causa de um relatório indicar Valores Presentes Líquidos negativos para os mesmos.

Para Martins (2001) todos os métodos de avaliação de empresas, na verdade, não são substitutos uns dos outros, mas sim complementares entre si, uma vez que cada um deles atende determinados objetivos e análises, devendo ser utilizados em conjunto e não de forma separada. Todos os métodos têm como objetivo evidenciar o patrimônio da empresa. 


\section{Métodos e procedimentos de coleta e de análise de dados do estudo}

Este capítulo expõe a forma como os dados da empresa Lojas Americanas S.A foram coletados, suas limitações e qual o tratamento que foi dado as informações coletadas.

\subsection{Procedimentos e instrumentos de coleta de dados utilizados no estudo}

Foram utilizadas fontes variadas de coleta de dados para se obter informações sobre a companhia e as premissas necessárias para realizar as projeções propostas.

A internet, pela sua acessibilidade e pela elevada disponibilidade de dados secundários, foi o principal meio para a coleta de dados através de informações públicas divulgadas sobre a companhia e o mercado, além de dados macroeconômicos.

O site de relação com investidores da Lojas Americanas S.A foi um dos maiores provedores de informações, de onde foram tirados os demonstrativos contábeis de 2013 a 2016, que foram usados para o cálculo do fluxo de caixa descontado dos últimos três anos, servindo assim de base para a realização do valuation. Além disso, o site também forneceu informações adicionais sobre a história da empresa, governança corporativa, contexto operacional, dentre outros.

\subsection{Formas de tratamento e análise dos dados coletados para o estudo}

Com o objetivo de realizar o Valuation da empresa, através do método de fluxo de caixa descontado, os dados foram coletados até que todas as informações necessárias tivessem sido obtidas.

As informações foram analisadas se estão coerentes com o objetivo de estudo e acrescentadas ao modelo caso tenham apresentado relevância. 


\section{Valuation das Lojas Americanas}

\subsection{Fluxo de Caixa Descontado}

A seguir serão apresentados e explicados os parâmetros utilizados no modelo de fluxo de caixa descontado.

\subsubsection{Projeções Macroeconômicas}

\begin{tabular}{|c|c|c|c|c|c|c|c|c|c|c|c|}
\hline \begin{tabular}{|l|} 
Projeções \\
Macroeconomicas
\end{tabular} & 2017P & 2018P & 2019P & 2020P & 2021P & $2022 \mathrm{P}$ & 2023P & $2024 \mathrm{P}$ & $2025 \mathrm{P}$ & $2026 \mathrm{P}$ & 2027P \\
\hline Crescimento Real do PIB & $0,82 \%$ & $2,98 \%$ & $3,40 \%$ & $2,44 \%$ & $2,20 \%$ & $2,34 \%$ & $2,34 \%$ & $2,34 \%$ & $2,34 \%$ & $2,34 \%$ & $2,34 \%$ \\
\hline Inflação (IPCA) & $2,96 \%$ & $3,79 \%$ & $3,83 \%$ & $3,72 \%$ & $3,78 \%$ & $3,86 \%$ & $3,86 \%$ & $3,86 \%$ & $3,86 \%$ & $3,86 \%$ & $3,86 \%$ \\
\hline CPI - Inflação Americana & $1,86 \%$ & $2,49 \%$ & $2,43 \%$ & $2,43 \%$ & $2,43 \%$ & $2,43 \%$ & $2,43 \%$ & $2,43 \%$ & $2,43 \%$ & $2,43 \%$ & $2,43 \%$ \\
\hline $\mathrm{CDI}$ & $7,00 \%$ & $6,38 \%$ & $6,38 \%$ & $6,88 \%$ & $6,88 \%$ & $6,88 \%$ & $6,88 \%$ & $6,88 \%$ & $6,88 \%$ & $6,88 \%$ & $6,88 \%$ \\
\hline
\end{tabular}

Tabela 2 - Projeções Macroeconômicas - Fonte: Itaú BBA

Foram utilizadas as projeções de longo prazo feitas pelo Itaú BBA e disponíveis ao público para a inflação (IPCA), taxa CDI, crescimento real do PIB e, para a inflação americana, o CPI (Consumer Price Index), uma vez que a empresa possui títulos da dívida em moeda estrangeira.

\subsubsection{Custo da dívida (Kd)}

A Lojas Americanas S/A possui um composição diversificada de credores, títulos de dívida e debêntures. Para se chegar ao custo da dívida (Kd) utilizado posteriormente para o cálculo do WACC, primeiro analisamos a estrutura da dívida reportada nos demonstrativos contábeis da empresa nos últimos anos: 


\begin{tabular}{|c|c|c|c|c|c|c|c|c|}
\hline Composição & \multirow{2}{*}{\multicolumn{2}{|c|}{2013}} & \multirow{2}{*}{\multicolumn{2}{|c|}{2014}} & \multirow{2}{*}{\multicolumn{2}{|c|}{2015}} & \multirow{2}{*}{\multicolumn{2}{|c|}{2016}} \\
\hline Em moeda nacional & & & & & & & & \\
\hline BNDES (a) & $\mathrm{RS}$ & $607.625,00$ & $\mathrm{R} \$$ & $746.617,00$ & $\mathrm{RS}$ & $747.229,00$ & $\mathrm{R} \$$ & $602.690,00$ \\
\hline BNDES (a) & & & $\mathrm{R} \$$ & $92.933,00$ & $\mathrm{R} \$$ & $76.020,00$ & $\mathrm{R} \$$ & $97.441,00$ \\
\hline BNDES (a) & & & $\mathrm{R} \$$ & $232.478,00$ & $\mathrm{RS}$ & $740.466,00$ & $\mathrm{R} \$$ & $853.053,00$ \\
\hline FINEP & & & $\mathrm{R} \$$ & $79.555,00$ & $\mathrm{R} \$$ & $269.165,00$ & $\mathrm{RS}$ & $278.778,00$ \\
\hline Capital de Giro & $\mathrm{R} \$$ & $2.192 .612,00$ & $\mathrm{R} \$$ & $1.603 .721,00$ & $\mathrm{RS}$ & $3.054 .262,00$ & $\mathrm{R} \$$ & $3.711 .994,00$ \\
\hline Quotas FIDC & $\mathrm{R} \$$ & $1.226 .039,00$ & $\mathrm{R} \$$ & $1.230 .355,00$ & $\mathrm{RS}$ & $1.236 .478,00$ & $\mathrm{R} \$$ & $1.236 .082,00$ \\
\hline \multicolumn{9}{|c|}{ Em moeda estrangeira (b) } \\
\hline Capital de Giro (c) & $\mathrm{R} \$$ & $914.651,00$ & $\mathrm{R} \$$ & $807.343,00$ & $\mathrm{R} \$$ & $1.518 .552,00$ & $\mathrm{R} \$$ & $1.417 .196,00$ \\
\hline Operaçốes de swap & -RS & $83.008,00$ & -RȘ & $162.059,00$ & -RȘ & $287.720,00$ & $\mathrm{RS}$ & $118.980,00$ \\
\hline TOTAL & & $4.857 .919,00$ & & $4.630 .943,00$ & & 7.354.452,00 & & $8.316 .214,00$ \\
\hline
\end{tabular}

Tabela 3 - Estrutura da divida LASA 2013 a 2016 - Fonte: Relatórios anuais

Depois, determinamos a proporção de cada tipo de dívida sobre o total devido:

\begin{tabular}{|c|c|c|c|c|}
\hline Composição & \multirow{2}{*}{2013} & \multirow{2}{*}{2014} & \multirow{2}{*}{2015} & \multirow{2}{*}{2016} \\
\hline Em moeda nacional & & & & \\
\hline BNDES (a) & $12,51 \%$ & $16,12 \%$ & $10,16 \%$ & $7,25 \%$ \\
\hline BNDES (a) & & $2,01 \%$ & $1,03 \%$ & $1,17 \%$ \\
\hline \begin{tabular}{|l} 
BNDES (a) \\
\end{tabular} & & $5,02 \%$ & $10,07 \%$ & $10,26 \%$ \\
\hline FINEP & & $1,72 \%$ & $3,66 \%$ & $3,35 \%$ \\
\hline \begin{tabular}{|l|} 
Capital de Giro \\
\end{tabular} & $45,13 \%$ & $34,63 \%$ & $41,53 \%$ & $44,64 \%$ \\
\hline Quotas FIDC & $25,24 \%$ & $26,57 \%$ & $16,81 \%$ & $14,86 \%$ \\
\hline \multicolumn{5}{|l|}{$\begin{array}{l}\text { Em moeda } \\
\text { estrangeira (b) }\end{array}$} \\
\hline \begin{tabular}{|c|} 
Capital de Giro (c) \\
\end{tabular} & $18,83 \%$ & $17,43 \%$ & $20,65 \%$ & $17,04 \%$ \\
\hline Operações de swap & $-1,71 \%$ & $-3,50 \%$ & $-3,91 \%$ & $1,43 \%$ \\
\hline
\end{tabular}

Tabela 4 - Peso da composição da dívida - Fonte: Relatórios anuais

E multiplicamos a proporção pelo custo especifico de cada tipo de credito tomado pela empresa:

\begin{tabular}{|l|l|}
\hline \multicolumn{2}{|c|}{ Custo da Divida } \\
\hline BNDES (a) & TJLP $+1,4 \%$ a.a \\
\hline BNDES (a) & $6 \%$ a.a \\
\hline BNDES (a) & Selic + até 3,68 a.a \\
\hline FINEP & $4 \%$ a.a \\
\hline Capital de Giro & $132 \%$ do CDI \\
\hline Quotas FIDC & $108,9 \%$ do CDI \\
\hline \multicolumn{2}{|c|}{ Em USD } \\
\hline Capital de Giro (c) & CPI + juros de $7,89 \%$ \\
\hline Operações de swap & $112,95 \%$ do CDI \\
\hline
\end{tabular}

Tabela 5 - Custo de crédito - Fonte: Relatórios anuais 
Encontrando assim o custo da dívida ponderado dos últimos 4 anos de exercício:

\begin{tabular}{|l|c|c|c|c|}
\hline $\begin{array}{l}\text { Custo } \\
\text { ponderado da }\end{array}$ & 2013 & 2014 & 2015 & 2016 \\
\cline { 2 - 5 } divida & $11 \%$ & $11,87 \%$ & $14,46 \%$ & $15,11 \%$ \\
\hline
\end{tabular}

Tabela 6 - Custo da dívida - Fonte: Relatórios anuais

Para a modelagem do fluxo de caixa descontado, utilizou-se o valor mais atual de $15,11 \%$ para o cálculo do WACC.

Consideramos que inferir crescimento do custo da dívida não seria adequado, pois já se trata de uma alta histórica. Ao mesmo tempo, utilizar a média seria apenas arbitrário e não refletiria a situação atual da empresa sob o cenário econômico mais recente.

\subsubsection{Custo de Capital Próprio (Ka)}

Para o cálculo do capital próprio foi utilizado o modelo CAPM, conforme a equação 3 (página 9).

O Beta utilizado foi de 0,66 , encontrado no site da agência de informações britânica Reuters.

O prêmio de risco do mercado foi de 9,96\%, que é o prêmio histórico para ações do mercado brasileiro apurado pelo Professor Damodaran e divulgado em seu site. A taxa de livre de risco utilizada como parâmetro o yield do US T-Note de 10 anos, que será de 2,3\%. Também foi adicionado o Risco país, de 255 pontos divulgado pelo Banco JP Morgan. 
Por fim, usou-se o diferencial entre a inflação americana e a Brasileira para transformar o custo de Dólares (US\$) em Reais (R\$)

Com as informações acima, foi estimado o Custo de Capital Próprio real de $12,42 \%$.

\begin{tabular}{|l|c|}
\hline CAPM $=\mathbf{R f}+\boldsymbol{\beta}^{*}[\mathbf{R m}$ - Rf], onde: & Valor \\
\hline $\mathrm{Rf}=$ taxa de juros livre de riscos & $2,30 \%$ \\
\hline $\begin{array}{l}\beta=\text { representa a sensibilidade dos } \\
\text { retornos do ativo em relação aos do } \\
\text { mercado }\end{array}$ & 0,65 \\
\hline $\begin{array}{l}\text { Rm - Rf = prêmio de mercado ou } \\
\text { prêmio de risco }\end{array}$ & $9,96 \%$ \\
\hline Risco País & $2,55 \%$ \\
\hline Inflação Brasileira & $2,96 \%$ \\
\hline Inflação Americana & $1,86 \%$ \\
\hline CAPM = Custo do capital próprio & $12,42 \%$ \\
\hline
\end{tabular}

Tabela 7 - CAPM

\subsubsection{WACC - Weighted Average Capital Cost (Custo Médio Ponderado do Capital)}

O WACC é a estimativa do custo de capital da empresa, taxa de desconto utilizada na modelagem para trazer os fluxos de caixa futuros a valores presentes e que representa a taxa mínima que a empresa precisa cobrir para cobrir suas dívidas e remunerar adequadamente seus acionistas pelo risco incorrido.

Aplicamos a fórmula utilizando os custos de capital próprio que encontramos com a fórmula de CAPM, o custo da dívida ponderado que encontramos ao analisar as dívidas da empresa e os valores de dívida e patrimônio líquido encontrados nos demonstrativos contáveis. 


\begin{tabular}{|c|c|}
\hline$W A C C=K p l[P L /(P L+D)]+K D[D /(P L+D)]^{*}(1-t)$ & Valor \\
\hline $\mathrm{Kpl}=$ custo do capital próprio & $12,42 \%$ \\
\hline PL = Patrimônio líquido a valor de mercado & $24.315 .177,44$ \\
\hline $\mathrm{Kd}=$ custo da dívida & $15,11 \%$ \\
\hline $\mathrm{D}=$ dívida a valor de mercado & $8.316 .214,00$ \\
\hline$(1-t)=$ Beneficio fiscal $/ / t=34 \%$ & 0,66 \\
\hline WACC $=$ & $11,80 \%$ \\
\hline
\end{tabular}

Tabela 8 - Cálculo WACC

O resultado encontrado é o WACC de $11,80 \%$.

\subsubsection{Premissas de Crescimento}

O faturamento da companha é composto pela venda de produtos, através de suas lojas físicas ou canais eletrônicos. No total são mais de 80 mil itens de 4 mil empresas diferentes.

A vasta diversificação de produtos e o posicionamento de mercado, tendo grande parte de seus clientes nas classes B, C e D, nos levou a inferir que o crescimento da empresa está intimamente ligado ao da economia do país, fato esse reforçado pelos resultados recentes face a crise econômica brasileira. Por esses motivos entendeu-se como adequado usar a projeção do PIB, apresentada no tópico 4.3.1, como crescimento para a Receita Bruta.

Os impostos sobre produtos vendidos foram mantidos em $15 \%$, nível verificado em 2015 e 2016. Foram mantidas as mesmas proporções para o custo das mercadorias vendidas e serviços prestados, $70 \%$ da Receita líquida, nos últimos 4 anos.

Para as despesas operacionais foi utilizada correção pelo índice de inflação, IPCA, também no tópico 4.3.1 


\subsubsection{CAPEX e Depreciação \& Amortização}

Para se chegar à projeção do CAPEX, uma análise foi feita do total investido nos últimos anos e seus valores utilizados para projetar o crescimento dos investimentos ao longo do período analisado.

Os investimentos podem ser divididos em três categorias, segundo os demonstrativos da empresa:

\begin{tabular}{|c|c|c|c|c|}
\hline (em milhares de reais) & 2013 & 2014 & 2015 & 2016 \\
\hline Inauguração / Melhorias & $\mathrm{R} \$ 505.700,00$ & $\mathrm{R} \$ 429.000,00$ & $\mathrm{R} \$ 452.600,00$ & $\mathrm{R} \$ 398.900,00$ \\
\hline Tecnologia & $\mathrm{R} \$ \mathbf{9 5 . 3 0 0 , 0 0}$ & $\mathrm{R} \$ 117.500,00$ & $\mathrm{R} \$ 129.800,00$ & $\mathrm{R} \$ 108.700,00$ \\
\hline Operações e outros & $\mathrm{R} \$ 31.800,00$ & $\mathrm{R} \$ 124.400,00$ & $\mathrm{R} \$ \$ \quad 94.900,00$ & $\mathrm{R} \$ \mathbf{5 3 . 3 0 0 , 0 0}$ \\
\hline TOTAL Investimento & 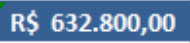 & $\mathrm{R} \$ \mathbf{6 7 0 . 9 0 0 , 0 0}$ & $\mathrm{R} \$ \mathbf{6 7 7 . 3 0 0 , 0 0}$ & $\mathrm{R} \$ \mathbf{5 6 0 . 9 0 0 , 0 0}$ \\
\hline
\end{tabular}

Tabela 9 - Capex 2013 a 2016

Com os números dos últimos anos em mão, foi determinado que investimentos em Tecnologia e Operações cresceriam na mesma proporção que as despesas, uma vez que é necessário que acompanhem a necessidade operacional da empresa.

Para os investimentos em novas unidades, foi decidido por 2 períodos antes da perpetuidade. O primeiro até 2019, por conta do plano de expansão "85 anos em 5", e o segundo de 2020 até 2027, onde o número de lojas abertas por ano deve retornar a média dos últimos anos de 100 por ano.

Como parte do plano de expansão " 85 anos em 5", a empresa planeja abrir 800 entre 2015 e 2019. Com 185 abertas nos últimos 2 anos e 200 planejadas para 2017, um média de 208 lojas deveram ser abertas em 2018 e 2019, uma vez que o plano de expansão ainda é aludido pela empresa como uma meta a ser alcançada.

Foi determinado então a relação entre Investimentos em inaugurações / Melhorias e o número de lojas abertas, para cada ano, e a média entre as proporções dos últimos 3 anos e de 2017 até o 3o trimestre. 


\begin{tabular}{|c|c|c|c|c|c|}
\hline \multicolumn{6}{|c|}{ Investimento em Inauguração/№ de Lojas inauguradas } \\
\hline (em milhares de reais) & 2013 & 2014 & 2015 & 2016 & $9 M 2017$ \\
\hline Inauguração / Melhorias & $\mathrm{R} \$ 505.700,00$ & $\mathrm{R} \$ 429.000,00$ & $\mathrm{R} \$ 452.600,00$ & $\mathrm{R} \$ 398.900,00$ & $\mathrm{R} \$ 518.400,00$ \\
\hline Número de Lojas abertas & 109 & 118 & 92 & 93 & 82 \\
\hline Custo por Loja & $5.805,50$ & $5.685,59$ & $7.361,96$ & $6.031,18$ & $6.321,95$ \\
\hline
\end{tabular}

\section{\begin{tabular}{|l|ll|} 
Custo médio por loja 2013 - 2017 & R\$̣ $\quad 6.241,24$ \\
\hline
\end{tabular}}

Tabela 10 - Investimento/ № lojas inauguradas 2013 a 2016

Esse número foi então aplicado a nossa projeção de lojas para os próximos anos e acrescido pela inflação do período, uma vez que o custo para abrir uma loja aumentará ao longo dos anos.

Para o período até 2019, seguindo o plano de expansão "85 anos em 5", chegamos ao seguinte CAPEX:

\begin{tabular}{|c|c|c|c|c|c|}
\hline \multicolumn{6}{|c|}{ Capex $1^{\circ}$ período } \\
\hline (em milhares de reais) & & 2017P & & 2018P & 2019P \\
\hline Inauguração / Melhorias & $\mathrm{R} \$$ & $1.248 .407,53$ & & $1.347 .592,88$ & $\mathrm{R} \$ 1.341 .114,07$ \\
\hline Número de Lojas abertas & & 200 & & 208 & 207 \\
\hline Tecnologia & $\mathrm{R}$ & $113.866,67$ & $\mathrm{RS}$ & $118.185,88$ & $122.716,65$ \\
\hline Operações e ol & $\mathrm{R} \$$ & $31.733,33$ & $\mathrm{RSS}$ & $32.937,05$ & $34.199,72$ \\
\hline TOTAL Investimento & $\mathrm{RS}$ & $1.394 .207,53$ & & $1.498 .923,81$ & $\mathrm{R} \$ \mathbf{1} 1.498 .237,44$ \\
\hline
\end{tabular}

Tabela 11 - CAPEX Projetado Plano "85 Anos em 5"

E para o segundo período, com um plano de expansão normalizado:

\begin{tabular}{|c|c|c|c|c|c|c|c|c|}
\hline \multicolumn{9}{|c|}{ Capex $2^{\circ}$ período } \\
\hline (em milhares de reais) & 2020P & $2021 P$ & 2022P & 2023P & $2024 \mathrm{P}$ & $2025 \mathrm{P}$ & 2026P & 2027P \\
\hline Inauguração / Melhorias & $\mathrm{R} \$ \mathbf{6 4 8 . 1 3 3 , 2 0}$ & $\mathrm{R} \$ 6^{2} .445,45$ & $\mathrm{R} \$ 647.772,66$ & $\mathrm{R} \$ 648.274,72$ & $\mathrm{R} \$ \mathrm{~N}^{2} \mathrm{~s} .274,72$ & $\mathrm{R} \$ \mathrm{~N}^{2} .274,72$ & $\mathrm{R} \$ 648.274,72$ & $\mathrm{R} \$ 648.274,72$ \\
\hline Número de Lojas abertas & 100 & 100 & 100 & 100 & 100 & 100 & 100 & 100 \\
\hline Tecnologia & $\mathrm{R} \$ 127.285,89$ & $\mathrm{R} \$ 132.092,00$ & $\mathrm{R} \$ 137.185,81$ & $\mathrm{R} \$ 142.476,06$ & $\mathrm{R} \$ 147.970,32$ & $\mathrm{R} \$ 153.676,45$ & $\mathrm{R} \$ 159.602,62$ & $\mathrm{R} \$ 165.757,32$ \\
\hline Operações e outros & RS $35.473,12$ & $\mathrm{R} \$ \mathrm{~N}^{2} \quad 36.812,52$ & $\mathrm{R} \$ \quad 38.232,11$ & R\$ $39.706,44$ & $\mathrm{R} \$ \mathrm{~N}^{2} \quad 41.237,63$ & $\mathrm{R} \$ \mathrm{~N}^{2} .827,86$ & 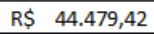 & $\mathrm{R} \$ 46.194,66$ \\
\hline TOTAL Investimento & RS 810.992,21 & R\$ 816.449,97 & RS $823.290,59$ & $\mathrm{R} \$ \mathbf{8 3 0 . 5 5 7 , 2 3}$ & R\$ 837.582,67 & R\$ $844.879,03$ & $\mathrm{R} \$ \mathbf{8 5 2 . 4 5 6 , 7 6}$ & $\mathrm{R} \$ \mathbf{8 6 0 . 3 2 6 , 7 0}$ \\
\hline
\end{tabular}

Tabela 12 - CAPEX até a perpetuidade 


\subsubsection{Capital de Giro}

Para estimar a necessidade de capital de giro, decidiu-se projetar as contas relevantes do Balanço patrimonial, seguindo as premissas e projeções já referidas. Para tanto, utilizou-se a média dos últimos 3 anos da proporção entre a conta do balanço patrimonial e uma relevante do DRE para completar a projeção.

As contas de tributos a recuperar, despesas antecipadas, obrigações sociais trabalhistas e obrigações fiscais foram projetadas como um percentual da renda liquida. As contas de estoques e fornecedores foram projetadas em dias de custo de mercadoria vendidos e as contas a receber como dias de receita líquida.

Com a projeção realizada, chegamos aos valores da tabela 13 a seguir, em milhões de reais: 


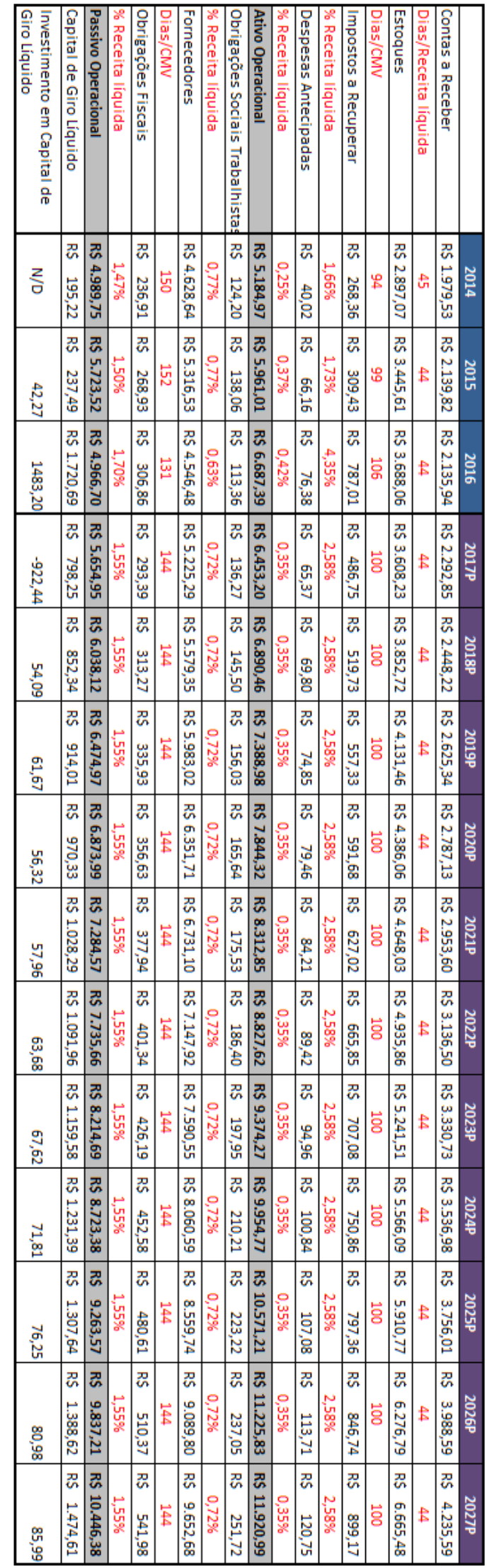

Tabela 13 - Projeção Capital de Giro 


\subsubsection{EBITDA e EBIT}

Com as análises apresentadas na seções anteriores, chegamos a esse EBITDA e EBIT (Tabela 14):

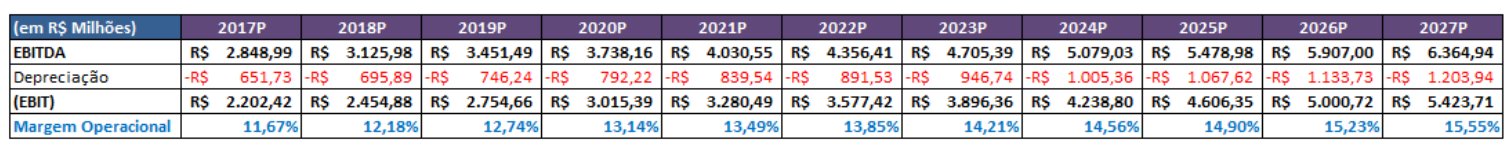

Tabela 14 - EBITDA e EBIT

\subsubsection{Valor presente dos fluxos operacionais}

Com as premissas adotadas, achou-se o fluxo de caixa do período projetado, que foi trazido a valor presente pela WACC encontrada para determinar o valor presente da empresa no período de projeção explicita, de $\mathrm{R} \$ 11.409,76$ milhões, conforme tabela 15.

\begin{tabular}{|c|c|c|c|c|c|c|c|c|c|c|c|c|c|c|}
\hline Fluxo de Caixa (em RȘ Milhões) & & $017 \mathrm{P}$ & & 018P & $2019 \mathrm{P}$ & $2020 \mathrm{P}$ & $2021 \mathrm{P}$ & $2022 \mathrm{P}$ & $2023 \mathrm{P}$ & $2024 \mathrm{P}$ & $2025 \mathrm{P}$ & 2026P & & 027P \\
\hline EBIT & $R S$ & $2.202,42$ & RS & $2.454,88$ & RS $2.754,66$ & RS $3.015,39$ & RS $3.280,49$ & $R \$ 3.577,42$ & RS $3.896,36$ & RS $\$ 4.238,80$ & R\$ 4.606,35 & RS $5.000,72$ & RS & $5.423,71$ \\
\hline - Imposto Operacional & $-R S$ & 748,82 & -R\$̦ & 834,66 & -RS 936,59 & - $\mathrm{R} \$ 1.025,23$ & $-R \$ 1.115,37$ & $-R \$ 1.216,32$ & $-\mathrm{R} \$ 1.324,76$ & -RS $1.441,19$ & $-\mathrm{R} \$ 1.566,16$ & -R\$ $1.700,24$ & $-R S$ & $1.844,06$ \\
\hline$=$ NOPAT & RS & $1.453,60$ & RS & $1.620,22$ & R\$ $1.818,08$ & R\$ $1.990,15$ & RS 2.165,12 & R\$ $2.361,10$ & R\$ $2.571,60$ & R\$ $2.797,61$ & RS $3.040,19$ & R\$ $3.300,47$ & $\mathrm{RS}$ & $3.579,65$ \\
\hline +Depreciação & $R S$ & 651,73 & RȘ & 695,89 & R\$ 746,24 & RS 792,22 & RS 839,54 & RS $\quad 891,53$ & RS $\quad 946,74$ & $R \$ 1.005,36$ & R\$ $1.067,62$ & $\mathrm{R} \$ 1.133,73$ & $R S$ & $1.203,94$ \\
\hline -CAPEX & $R S$ & $1.394,21$ & RȘ & $1.498,92$ & RS $1.498,24$ & \begin{tabular}{|l|l|} 
RS & 810,99 \\
\end{tabular} & RȘ 816,45 & RS $\quad 823,29$ & \begin{tabular}{|l|l|} 
RS 830,56 \\
\end{tabular} & 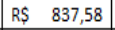 & \begin{tabular}{|l|l|} 
RS & 844,88 \\
\end{tabular} & RȘ 852,46 & $\mathrm{RSS}$ & 860,33 \\
\hline -Investimento em capital de giro lía & $R S$ & 54,09 & $\mathrm{RS}$ & 61,67 & RȘ 56,32 & 57,96 & 63,68 & 67,62 & 71,81 & 76,25 & 80,98 & 85,99 & $\mathrm{RS}$ & - \\
\hline$=$ Fluxo de Caixa Livre & $R S$ & 657,03 & $R S$ & 755,52 & $R \$ 1.009,75$ & R\$ $1.913,43$ & R\$ 2.124,54 & RS $2.361,72$ & RS 2.615,97 & RS $2.889,14$ & R\$ 3.181,96 & R\$ $3.495,76$ & $R S$ & $3.923,26$ \\
\hline WACC & & $11,80 \%$ & & & & & & & & & & & & \\
\hline =Fluxo de Caixa Descontado & $R S$ & 587,69 & RS & 604,46 & RS $\quad 722,60$ & RS $1.224,78$ & RS 1.216,38 & RS $1.209,47$ & RS $1.198,29$ & \begin{tabular}{|l|} 
RS $1.183,74$ \\
\end{tabular} & \begin{tabular}{|l|}
$R$ \\
\end{tabular} 1.166,12 & RS $1.145,92$ & $R S$ & $1.150,32$ \\
\hline Valor Presente & RS & 9,76 & & & & & & & & & & & & \\
\hline
\end{tabular}

Tabela 15 - Valor Presente dos Fluxos operacionais

\subsubsection{Perpetuidade}

Para calcular a perpetuidade, dividimos o valor da perpetuidade pela diferença entre a taxa de desconto e o valor de crescimento. Estipulou-se que o crescimento seria análogo ao da inflação, portanto utilizou-se o valor projetado do IPCA para 2026, 3,86\% para o crescimento.

Foi encontrado um valor de $\mathrm{R} \$ 14.487,67$ milhões para a perpetuidade. 


\begin{tabular}{|l|lr|}
\hline \multicolumn{2}{|c|}{ Perpetuidade (Em R\$ Milhões) } \\
\hline Fluxo em 2027P & R\$̦ & $1.150,32$ \\
\hline WACC & & $11,80 \%$ \\
\hline Crescimento & & $3,86 \%$ \\
\hline Total & RS & $\mathbf{1 4 . 4 8 7 , 6 7}$ \\
\hline
\end{tabular}

Tabela 16 - Perpetuidade

\subsubsection{Valor da Empresa e para os acionistas}

O valor encontrado para a empresa foi de $\mathrm{R} \$ 25.898,80$ milhões.

Para chegar ao valor para os acionistas, subtraímos o passivo oneroso, e somamos o caixa, as aplicações financeiras, impostos a recuperar, imposto de renda diferido e outros ativos não operacionais.

\begin{tabular}{|l|rr|}
\hline \multicolumn{3}{|c|}{ Valor para o Acionista (Em RS Milhões) } \\
\hline Valor da empresa (Em R\$ Milhões) & $\mathrm{R} \$$ & $25.898,80$ \\
\hline + Caixa e aplicações financeiras & $\mathrm{R} \$$ & $6.498,33$ \\
\hline - Passivo Oneroso & $-\mathrm{R} \$$ & $11.608,52$ \\
\hline +Imposto de renda e Contribuição Social Diferido & $\mathrm{R}$ & 769,44 \\
\hline +Impostos a recuperar e demais contas a receber & $\mathrm{R} \$$ & $2.151,95$ \\
\hline +Outros ativos/passivos não operacionais & $\mathrm{R} \$$ & 388,08 \\
\hline Total & $\mathrm{R} \$$ & $24.098,08$ \\
\hline
\end{tabular}

Tabela 17 - Valor para o acionista

\subsubsection{Valor das Ações}

Na data analisada, a empresa possuía mais de 1 bilhão e meio de ações emitidas, entre ordinárias e preferenciais. Assim o valor médio por ação encontrado foi de $R \$ 15,09$.

\begin{tabular}{|l|r|}
\hline Valuation & R\$ $24.098 .082 .018,97$ \\
\hline LAME3 & 539.943 .630 \\
\hline LAME\$ & 1.057 .250 .774 \\
\hline Valor por ação & 15,09 \\
\hline
\end{tabular}

Tabela 18 - Valor por ação 


\section{Conclusões}

O trabalho analisou a situação de uma das maiores empresas de varejo do país, um dos setores mais expostos a situação econômica geral, justamente durante a pior crise econômica das últimas décadas.

Enquanto que a perspectiva é de eventual melhora, a análise de fluxo de caixa feita de forma conservadora nos levou a manter as estimativas de crescimento num patamar modesto e resultou um downside em relação ao preço praticado pelo mercado.

O fluxo de caixa do projeto nos levou a um valor justo de $R \$ 15,09$ para as ações das Lojas Americanas, enquanto que o valor praticado pelo mercado é de $R \$ 15,31$ para ações preferenciais, uma diferença de $1,44 \%$.

Apesar do cenário, as Lojas Americanas parece obstinada em continuar sua expansão, consolidar sua posição nos diversos canais e países em que é player e está disposta a diversificar seu portfólio com serviços financeiros e formatos diferenciados de lojas, sendo testados atualmente no Rio de Janeiro.

Seu plano atual de expansão tem a ambição de dobrar o número de lojas no Brasil, entre 2015 e 2019. A empresa continua a investir na consolidação da posição da B2W como líder do varejo eletrônico e, segundo a última conferência eletrônica fechando o $3^{\circ}$ trimestre de 2017 , suas 3 lojas teste no novo formato conveniência tem tido resultados positivos e conseguido se diferenciar das lojas de bairro, o que pode apontar para uma nova oportunidade de crescimento. 


\section{REFERÊNCIAS}

ASSAF NETO, Alexandre. Finanças Corporativas e Valor. São Paulo: Atlas, 2008.

CASAROTTO FILHO, Nelson; KOPITTKE, Bruno Hartmut. Análise de investimentos. 10a․ ed. São Paulo: Atlas, 2007.

CATAPAN, E.A.; HEIDEMANN, F.G. Cálculo do custo de capital como método de avaliar empresas: variáveis essenciais. XXII Encontro Nacional de Engenharia de Produção. Curitiba - PR, 23 a 25 de outubro de 2002.

ENDLER, L. Avaliação de empresas pelo método de fluxo de caixa descontado e os desvios causados pela utilização de taxas de desconto inadequadas. ConTexto, Porto Alegre, v. 4, n. 6, $1^{\circ}$ semestre 2004.

MARTINS, Elizeu (org.). Avaliação de Empresas: Da Mensuração Contábil à Econômica. FIPECAFI, São Paulo, Atlas, 2001.

ROGERS, P.; DAMI, A.B.T.; RIBEIRO, K.C.S. Fluxo de caixa descontado como método de avaliação de empresas: o estudo de caso da Petrobrás Distribuidora S.A. XXIV Encontro Nac. de Eng. de Produção - Florianópolis, SC, Brasil, 03 a 05 de nov de 2004.

ROSS, Stephen A.; WESTERFIELD, Randolph, W.; JORDAN, Bradford D. Princípios de Administração Financeira. 2ª edição, São Paulo: Atlas, 2000.

SANTOS, Elieber Mateus dos \& PAMPLONA, Edson de Oliveira. Captando o Valor da Flexibilidade Gerencial Através da Teoria das Opções Reais. XXI Encontro Nacional de Engenharia de Produção, Salvador, Bahia, Out/2001.

TIBÚRCIO, César Augusto; CUNHA, Jameson Reinaux. Questões para avaliação de empresas na nova economia. Revista Contexto. Porto Alegre. RECON/UFRGRS, v.4, 2002.

Copeland, Tom; Koller, Tim; Murrin, Jack. Avaliação de Empresas - Valuation: Calculando e gerenciando o valor das empresas. 3.ed. São Paulo: Pearson, 2002.

B2W Companhia Digital. Relação com Investidores. Disponível em: <https://ri.b2w.digital/>. Acesso em Outubro e Novembro, 2017

Banco Itaú BBA. Análises Econômicas: Projeções Longo Prazo - Maio 2017. Disponível em: <https://www.itau.com.br/itaubba-pt/analises-economicas/projecoes >. Acesso em Outubro e Novembro, 2017

Estadão. Economia e Negócios. Disponível em $<$ http://economia.estadao.com.br/noticias/geral,varejo-tem-maior-queda-em-16anos,10000099107>. Acesso em Outubro e Novembro, 2017 
FGV IBRE. Índices Gerais de Preços < http://portalibre.fgv.br/main.jsp?lumChannelld=402880811D8E34B9011D92B6160B0 D7D >. Acesso em: 25 de outubro de 2016

Damodaran, Aswath. Avaliação de Investimentos: Ferramentas e técnicas para a determinação do valor de qualquer ativo. 2.ed. Rio de Janeiro: Qualitymark, 2009.

Damodaran Online. Data: Current. Disponível em: <http://pages.stern.nyu.edu/ adamodar/>. Acesso em Outubro de 2017.

ADVFN. Informações mercado mobiliário. Disponível em: http://br.advfn.com/indicadores/pnad. Acesso em: Outubro de 2017

IPEA. Ipeadata. Disponível em: $<$ http://www.ipeadata.gov.br/ExibeSerie.aspx?serid=40940\&module=M>. Acesso em: $11 \mathrm{de}$ maio de 2017.

Sociedade Brasileira de Varejo e Consumo: SBVC. Disponivel em: http://sbvc.com.br/. Acesso em: Outubro 2017. 


\section{Anexo 1}

กิ

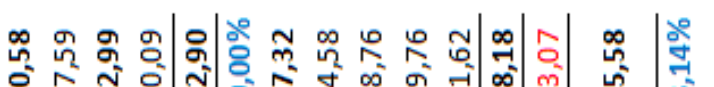

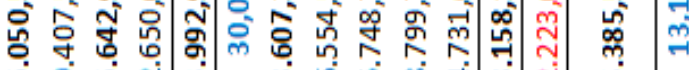

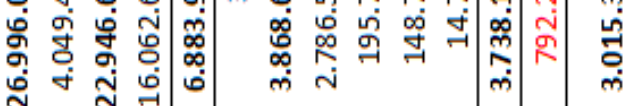

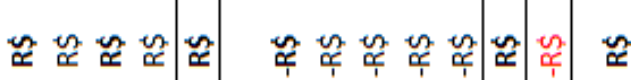
곡 웅 :

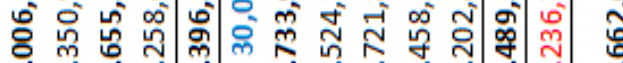

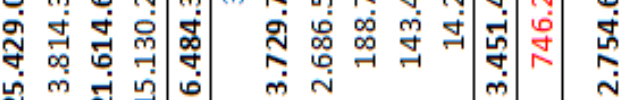
กิ m

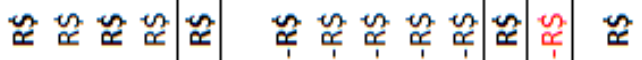

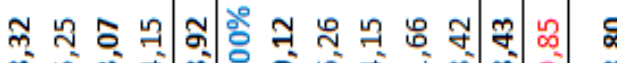

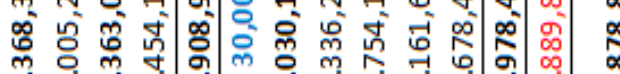

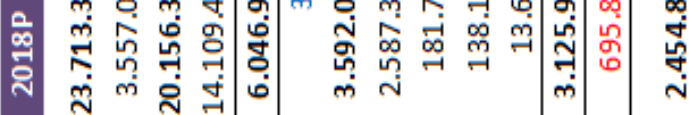

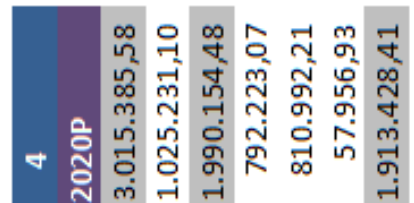
雍

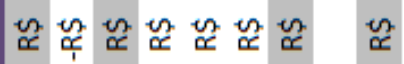

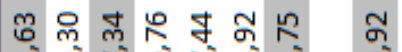

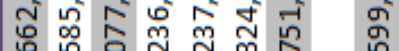

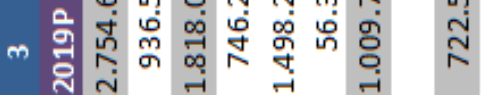

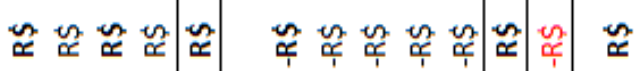

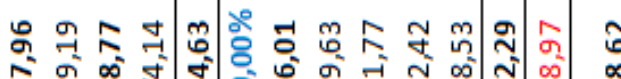

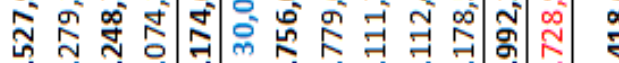

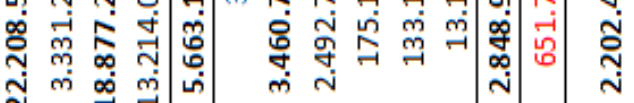

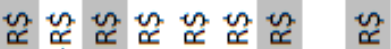

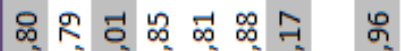
๓ ๓

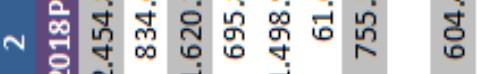

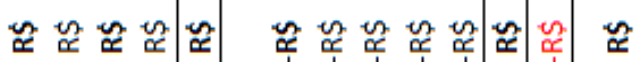

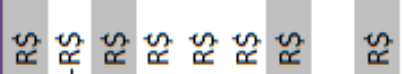

wa w w w w w w

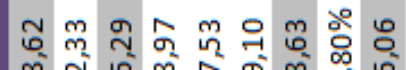

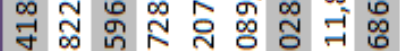

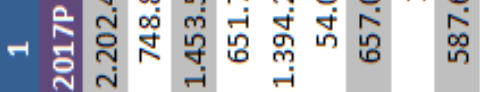

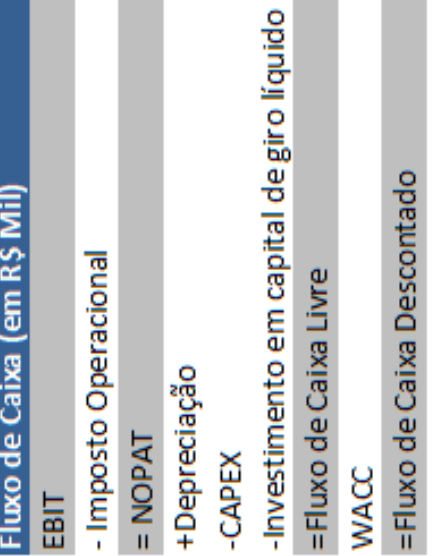


Anexo 2

ลิ

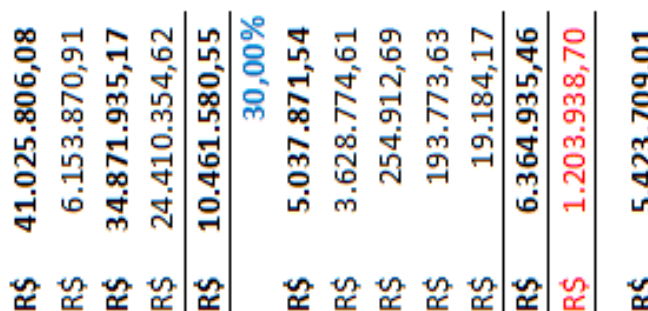
สิ ศิ สุ

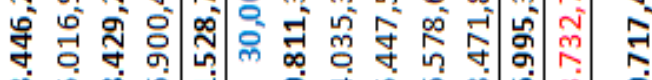

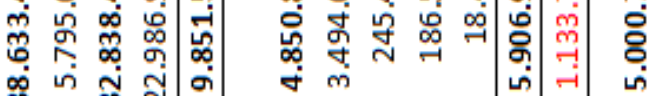
क तก तี่

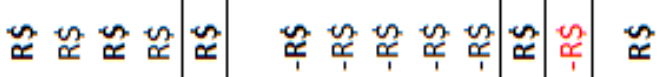

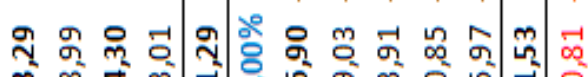

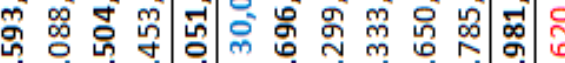

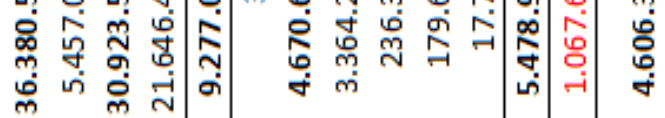
m $n$ त

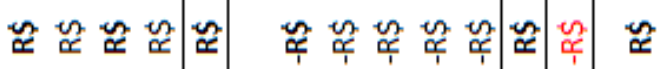
สี ๓

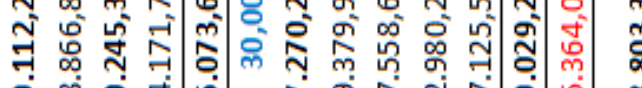
兽

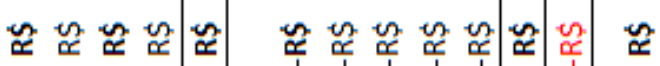
구 m

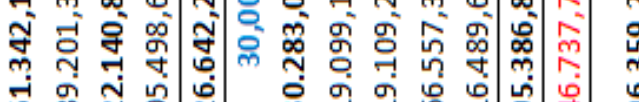

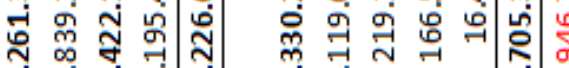
त्रं

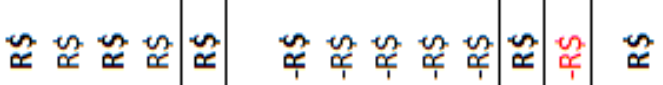
구

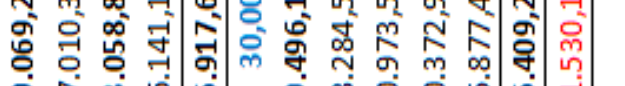

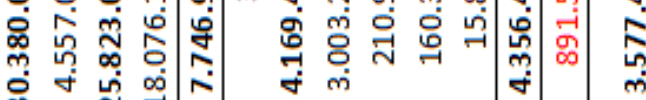

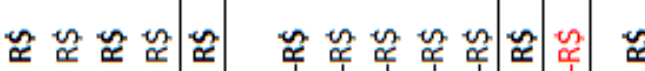

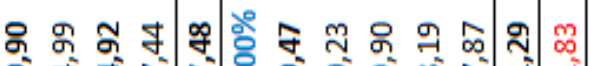

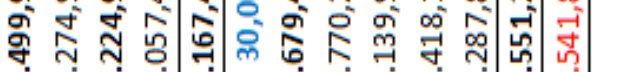
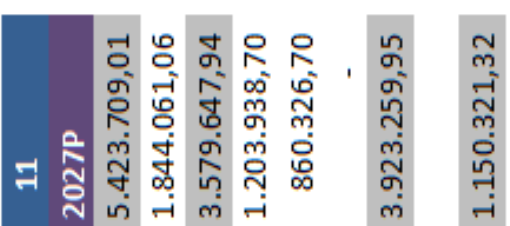

w w w w w w w w w w w w ㅇำำำ กัm m 궈ำ

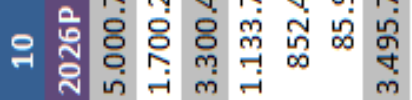

w w w w w w w w w w w w w w

ติ

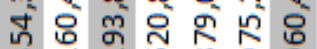

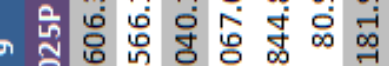
तु่

w w w w w w w w w w

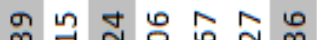
mं ติ

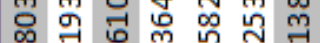

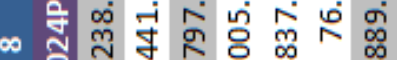
4ิ่

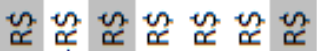
궉의

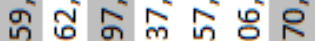
mร भก था

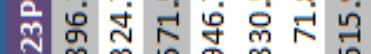
तิ

we w w w w

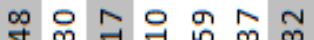
สิ กิ ช $m$ สิกี่ ลิ กึ่

we w w w w w w w

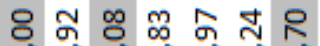
$\infty$ nन

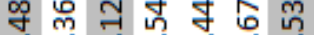
สิ จุ สิ 䑰 